\title{
Distinct urinary glycoprotein signatures in prostate cancer patients
}

\author{
Rebeca Kawahara ${ }^{1}$, Fabio Ortega², Livia Rosa-Fernandes ${ }^{3}$, Vanessa Guimarães ${ }^{2}$, \\ Daniel Quina ${ }^{1}$, Willian Nahas ${ }^{4}$, Veit Schwämmle ${ }^{3}$, Miguel Srougi ${ }^{2}$, Katia R.M. Leite ${ }^{2}$, \\ Morten Thaysen-Andersen ${ }^{5}$, Martin R. Larsen ${ }^{3}$ and Giuseppe Palmisano ${ }^{1}$ \\ ${ }^{1}$ Instituto de Ciências Biomédicas, Departamento de Parasitologia, Universidade de São Paulo, USP, São Paulo, Brazil \\ ${ }^{2}$ Laboratório de Investigação Médica da Disciplina de Urologia da Faculdade de Medicina da USP, LIM55, São Paulo, Brazil \\ ${ }^{3}$ Department of Biochemistry and Molecular Biology, University of Southern Denmark, Odense, Denmark \\ ${ }^{4}$ Instituto do Câncer do Estado de São Paulo, ICESP, São Paulo, Brazil \\ ${ }^{5}$ Department of Molecular Sciences, Macquarie University, Sydney, NSW, Australia \\ Correspondence to: Giuseppe Palmisano, email: palmisano.gp@usp.br \\ Keywords: prostate cancer; urine; glycopeptide; TMT-labeling; glycoproteomics \\ Received: April 04, $2018 \quad$ Accepted: July 31, $2018 \quad$ Published: September 04, 2018 \\ Copyright: Kawahara et al. This is an open-access article distributed under the terms of the Creative Commons Attribution License \\ 3.0 (CC BY 3.0), which permits unrestricted use, distribution, and reproduction in any medium, provided the original author and \\ source are credited.
}

\section{ABSTRACT}

Novel biomarkers are needed to complement prostate specific antigen (PSA) in prostate cancer ( $\mathrm{PCa}$ ) diagnostic screening programs. Glycoproteins represent a hitherto largely untapped resource with a great potential as specific and sensitive tumor biomarkers due to their abundance in bodily fluids and their dynamic and cancer-associated glycosylation. However, quantitative glycoproteomics strategies to detect potential glycoprotein cancer markers from complex biospecimen are only just emerging. Here, we describe a glycoproteomics strategy for deep quantitative mapping of $\boldsymbol{N}$ - and $\mathrm{O}$-glycoproteins in urine with a view to investigate the diagnostic value of the glycoproteome to discriminate $\mathrm{PCa}$ from benign prostatic hyperplasia (BPH), two conditions that remain difficult to clinically stratify. Total protein extracts were obtained, concentrated and digested from urine of six PCa patients (Gleason score 7) and six BPH patients. The resulting peptide mixtures were TMT-labeled and mixed prior to a multi-faceted sample processing including hydrophilic interaction liquid chromatography (HILIC) and titanium dioxide SPE based enrichment, endo-/exoglycosidase treatment and HILIC-HPLC pre-fractionation. The isolated $\mathbf{N}$ - and $\mathbf{O}$-glycopeptides were detected and quantified using high resolution mass spectrometry. We accurately quantified $729 \mathrm{~N}$-glycoproteins spanning 1,310 unique $\mathrm{N}$-glycosylation sites and observed 954 and 965 unique intact $\mathbf{N}$ - and $\mathbf{O}$-glycopeptides, respectively, across the two disease conditions. Importantly, a panel of 56 intact $\mathrm{N}$-glycopeptides perfectly discriminated PCa and BPH (ROC: AUC $=1$ ). This study has generated a panel of intact glycopeptides that has a potential for PCa detection.

\section{INTRODUCTION}

Prostate cancer (PCa) is the most common noncutaneous cancer and the second leading cause of cancer-related death in men [1]. Although blood levels of prostate specific antigen (PSA) is the most common diagnostic marker used for PCa screening, its low specificity has raised concerns regarding patient overdiagnosis and overtreatment [2]. For example, elevated serum PSA levels are associated with benign prostatic hyperplasia (BPH), a common age-related benign male condition, that shares similar clinical symptoms with 
malignant prostate disorders [3]. The urgent need for novel biomarkers that can effectively stratify $\mathrm{BPH}$ and $\mathrm{PCa}$ patients has prompted scientists to search for $\mathrm{PCa}$-specific biomolecules in bodily fluids.

Urine is an attractive excreted body fluid for PCa biomarker discovery, since it is readily obtained in a noninvasive manner and may, due to the proximity to the prostate, carry biomolecular signatures that reflect the aberrant biochemical processes occurring within the prostate during PCa development and progression [4, 5]. Mass spectrometry-based proteomics has been instrumental in the discovery of several candidate biomarkers in urine from PCa patients [6]. For example, Ahmad et al. [7] reported unusually low urinary levels of fibronectin and TP53INP2 in PCa patients compared to BPH patients. Jedinak et al. [8] reported a panel of differentially expressed proteins in PCa compared to BPH urine including $\beta$-2-microglobulin $(\beta 2 \mathrm{M})$, pepsinogen 3 (PGA3), and mucin 3 (MUC3). These examples illustrate that sensitive quantitation of aberrant protein signatures directly in urine is now technically feasible using modern LC-MS/MS technologies. However, disappointingly few of the proposed biomarker candidates for $\mathrm{PCa}$ diagnosis have been validated across multiple large $\mathrm{PCa}$ patient cohorts and none is, to the best of our knowledge, implemented in the clinic for PCa screening.

Protein glycosylation is increasingly being recognized as a modification with a great potential for cancer diagnostics [9-15]. Aberrations in the glycosylation machinery leading to "tumor-specific" glycan structures or epitopes are universal feature of malignant transformation and tumor progression [16-18]. Vermassen et al. showed that glycan profiling of urinary proteins could discriminate PCa from BPH patients [19]. In that specific study, $N$-glycans were released from urinary glycoproteins, labeled with with 8-aminopyrene-1,3,6-trisulphonic acid and analyzed by a multi-capillary electrophoresis-based sequencer. However, no site-specific information of the aberrant glycans that showed core fucosylation features associated with PCa could be derived from this glycomics focused approach. In another study, core fucosylation was observed as an enriched glyco-feature in PCa cell lines derived from metastatic cells relative to non-tumorigenic prostate cells [20]. It remains unclear if such PCa cell lines accurately reflect the glyco-phenotype of PCa tissue.

Liu et al. used mass spectrometry to explore former $N$-glycosylated peptides (hereafter de- $N$-glycosylated peptides or de- $N$-glycopeptides) in normal prostate, nonaggressive, aggressive and metastatic PCa tissues [21]. In total, 1,430 N-glycosylation sites were identified and some glycoproteins were proposed as biomarker candidates for PCa aggressiveness including $\mathrm{N}$-acylethanolamine acid amidase and protein tyrosine kinase 7. Cima et al. applied label-free quantitative proteomics to measure perturbations in the prostate and serum glycoproteome of Pten conditional knockout mice relative to matching wildtype mice. In that study, promising candidate biomarkers, such as thrombospondin-1 (THBS1), tissue inhibitor of metalloproteinase 1 (TIMP-1), complement factor $\mathrm{H}(\mathrm{CFH})$, and prolow-density lipoprotein receptorrelated protein 1 (LRP-1), were further validated by quantitative selected reaction monitoring (SRM) and ELISA in the sera of PCa and BPH patients [22]. Shah et al. showed altered fucosylation in the androgenindependent PCa cell line PC3 compared to the androgendependent PCa cell LNCap line using glycoproteomics. A total of 1,810 unique $N$-glycosylation sites from 653 $N$-glycoproteins were identified; 176 glycoproteins were present in different levels between the two cell lines [20]. Core fucosylation was observed as an enriched glycofeature in PCa cell lines derived from metastatic cells relative to non-tumorigenic prostate cells [20]. However, it remains unclear if such PCa cell lines accurately reflect the glyco-phenotype of PCa tissue.

Collectively, these studies have demonstrated the immense potential of present day mass spectrometry to map the glycoproteome and identify glycoproteins with untapped diagnostic potential to report on malignant transformation. However, to the best of our knowledge, no studies have to date profiled site-specific protein glycosylation features directly in urine from $\mathrm{PCa}$ and relevant control donors to investigate the potential of using aberrant glycoproteome signatures as accurate molecular reporters of $\mathrm{PCa}$ development and progression.

Despite of the impressive progress achieved in the now streamlined genome and proteome sequencing methods over the past decades, glycoproteomics technologies remain under-developed and are still only utilized in specialist laboratories [23, 24]. Technical challenges are still preventing or at least discouraging more general Proteomics focused laboratories. Key steps in the glycoproteomics workflow including glycopeptide enrichment, liquid chromatography-mass spectrometry (LC-MS/MS) acquisition and computational data analysis are still common bottlenecks that limit the identification rate and the quantitative accuracy when investigating the extensive micro- and macro-heterogeneity inherently associated with the $N$ - and $O$-glycoproteome $[25,26]$.

We recently described a method for site-specific characterization of the $N$-glycan composition, peptide carrier and glycosylation sites from urinary glycoproteins and endogenous glycopeptides of healthy donors [27]. Hydrophilic interaction liquid chromatography (HILIC) SPE-enriched glycopeptides were analyzed in their intact form by LC-MS/MS; in total, 472 unique $N$-glycosylation sites and 303 intact $N$-glycopeptides from 256 urinary $N$-glycoproteins were identified. Following on our previous work in urinary glycoproteomics, we here set out to expand our coverage of the urinary glycoproteome by combining complementary glycopeptide enrichment and pre-fractionation strategies with exo- and endoglycosidase digestion prior to LC-MS/MS. Importantly, we use isobaric labels to facilitate accurate quantitative 
glycoproteomics between and within donor groups to more effectively investigate the potential of intact glycopeptides as signatures for $\mathrm{PCa}$ detection and precise stratification from $\mathrm{BPH}$ conditions.

The innovative aspects of this study are summarized as follows: 1) we present a mass spectrometry-based method for a highly sensitive site-specific and quantitative characterization of the $\mathrm{N}$ - and $\mathrm{O}$-glycosylation decorating urinary proteins, 2) we used this method to obtain the largest map of human urinary glycoproteome to date including identifying glycosylated proteins, glycosylation sites and site-specific glycan compositions, and importantly 3) this method also showed that a panel of PCa-associated glycoproteins, as measured by intact glycopeptides, can be used to discriminate urine from PCa and BPH. Technical aspects pertaining to this glycoproteomics strategy and the panel of PCa-associated urinary glycoproteins are here discussed in the context of PCa detection and prostate biology.

\section{RESULTS}

\section{Quantitative glycoproteomics enable exploration of the urinary $\mathrm{N}$ - and $\boldsymbol{O}$-glycoproteome}

Urine samples $(\sim 2 \mathrm{ml})$ from six $\mathrm{PCa}$ and six $\mathrm{BPH}$ patients were obtained and investigated in this study. The PCa group included only patients with clinically validated adenocarcinoma with Gleason score 7 (GS 7), which denotes intermediate grade $\mathrm{PCa}$ relative to GS 6 representing low-risk $\mathrm{PCa}$ suitable for an active surveillance program, and the more advanced GS 8-10 representing high-risk $\mathrm{PCa}$ cases that generally are referred to immediate treatment. The serum PSA levels of the PCa patient group were $7.17 \pm 3.02 \mathrm{ng} / \mathrm{ml}(n=6)$ and $8.02 \pm 7.30 \mathrm{ng} / \mathrm{ml}$ in the BPH patient group $(n=6)$. As expected, no significant difference was observed in the serum PSA levels between these two patient groups ( $p \geq 0.05, n=6$, unpaired two-tailed $t$-test, Figure 1A) highlighting the shortcoming of this biomarker to accurately stratify PCa and BHP patients. Lower yields of total urinary protein were observed from two biological replicates from both the $\mathrm{PCa}$ and $\mathrm{BPH}$ groups; hence, these protein-poor samples were combined $(1: 1, \mathrm{w} / \mathrm{w})$ forming five biological replicates $(n=5)$ from each condition for comparative glycoproteomics.

Given the reasonably large protein starting material ( $\sim 100 \mu \mathrm{g} /$ replicate), we applied a multi-faceted quantitative LC-MS/MS-based glycoproteomics strategy to obtain a deep coverage of the urinary glycoproteome and investigate for differentially abundant glycoproteins in $\mathrm{PCa}$ and $\mathrm{BPH}$ urine. In short, after protein extraction, concentration and tryptic digestion of the 10 samples, the resulting peptide mixtures were labeled with an isobaric amine-reactive TMT10plex - peptides from the five $\mathrm{PCa}$ samples were labeled with TMT 126, 127N, 127C, 128N and $128 \mathrm{C}$ and peptides from the five $\mathrm{BPH}$ samples were labeled with TMT 129N, 129C, 130N, 130C and 131. All TMT-labelled peptide samples were then mixed in 1:1 $(\mathrm{w} / \mathrm{w})$ relationships prior to a multi-faceted glycopeptide enrichment and pre-fractionation sample processing (Figure 1B).

The glycopeptide enrichment was performed using two complementary solid phase extraction (SPE) strategies i.e. titanium dioxide $\left(\mathrm{TiO}_{2}\right) \mathrm{SPE}$ and HILIC SPE enrichment, to reach the deepest possible coverage of the urinary glycoproteome. The sialic acid-retaining $\mathrm{TiO}_{2} \mathrm{SPE}$ $[28,29]$ was included since we previously showed that urinary $N$-glycoproteins are highly sialylated [27]. HILIC SPE is widely recognized to capture all glycopeptides displaying a minimum degree of hydrophilicity regardless of the nature of their conjugated glycan structure [30, 31]; however, this enrichment method may come short of quantitatively capturing $O$ - and $N$-glycopeptides of very low hydrophilicity (unpublished observation). The $\mathrm{TiO}_{2}$ and HILIC SPE enriched glycopeptides were 1) analyzed directly in their intact form by high resolution LC-MS/MS on a Orbitrap Q-Exactive HF with HCD fragmentation, which provided information of the peptide carrier and site-specific glycan heterogeneity, or 2) treated simultaneously with $N$-glycosidase F (PNGase F) and sialidase A to generate de- $N$-glycosylated and desialo$O$-glycopeptides that are less challenging to characterize by LC-MS/MS. Combining the latter approach with a similar Orbitrap Q-Exactive HF HCD based acquisition, provided $N$-glycosylation site information and site-specific glycan information of the $O$-glycosylation. In addition, non-modified peptides that did not bind to the $\mathrm{TiO}_{2} \mathrm{SPE}$ column ("flow through") and PNGase F/sialidase-treated glycopeptides were pre-fractionated using off-line HILIC HPLC and the resulting fractions were analyzed by Orbitrap Q-Exactive HF HCD-MS/MS (Figure 1B).

\section{Complementary $\mathrm{TiO}_{2}$ and HILIC SPE-based glycopeptide enrichment provide deep coverage of the urinary glycoproteome}

Even without peptide pre-fractionation, the combined use of $\mathrm{TiO}_{2}$ and HILIC SPE facilitated the identification of 630 unique $N$-linked glycosylation sites belonging to $361 \mathrm{~N}$-glycoproteins across the urine samples (Supplementary Figure 1A, and Supplementary Tables 1-2). Partial overlap between the $\mathrm{TiO}_{2}$ and HILIC SPE enrichment approaches were observed when measured by the proportion of unique $\mathrm{N}$-glycosylation sites $(48 \%$, $304 / 630)$ and the corresponding glycoproteins (58\%, $211 / 361$ ) detected in both sample preparation techniques (Supplementary Figure 1B-1C). However, when assessed by the identified intact glycopeptides, the enrichment strategies displayed high complementarity: From a combined total of $954 \mathrm{~N}$ - and $210 \mathrm{O}$-glycopeptides identified with high peptide confidence $(0 \%$ peptide 
FDR Pep-2D) [32] (Supplementary Figure 1D and Supplementary Tables 3-6), the degree of unique $N$ - and $O$-glycopeptides identified from both the $\mathrm{TiO}_{2}$ and HILIC SPE preparations was 23\% (216/954) and 10\% (20/210), respectively (Supplementary Figure 1E-1F).

Due to the unbiased enrichment of the hydrophilic glycopeptides, HILIC SPE showed, as expected, a higher capture efficiency of $\mathrm{N}$-glycopeptides compared to $\mathrm{TiO}_{2}$ SPE. In contrast, $\mathrm{TiO}_{2}$ retained a greater number of $O$-glycopeptides compared to HILIC SPE indicating a high degree of sialylation of the $O$-glycopeptides and an inability of HILIC SPE to retain such lowly hydrophilic glycopeptides.
We also investigated the glycosylation features of the $\mathrm{TiO}_{2}$ and HILIC SPE enriched intact $N$-glycopeptides (Supplementary Figure 1G, Supplementary Tables 3-4) and $O$-glycopeptides (Supplementary Figure $1 \mathrm{H}$, Supplementary Tables 5-6). In agreement with our previous study [27], the urinary $\mathrm{N}$-glycoproteins were predominantly carrying complex and hybrid type $\mathrm{N}$-glycans with a high level of fucosylation and/or sialylation accounting for $\sim 85 \%$ of all identified intact $N$-glycopeptides (Supplementary Figure $1 \mathrm{G}$ ). Sialylated $O$-glycopeptides were also abundant $(\sim 70 \%)$ and were, as expected, efficiently enriched using $\mathrm{TiO}_{2}$ SPE (Supplementary Figure 1H). Collectively, these data clearly demonstrated that the parallel usage of HILIC
A

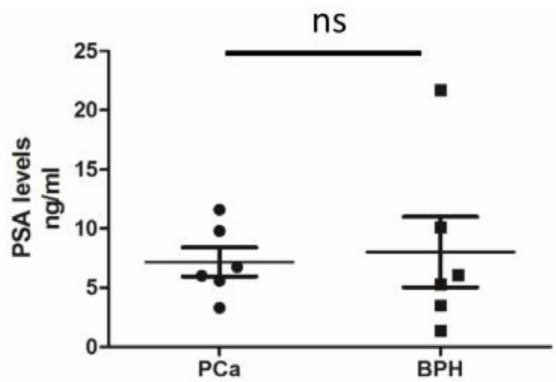

B
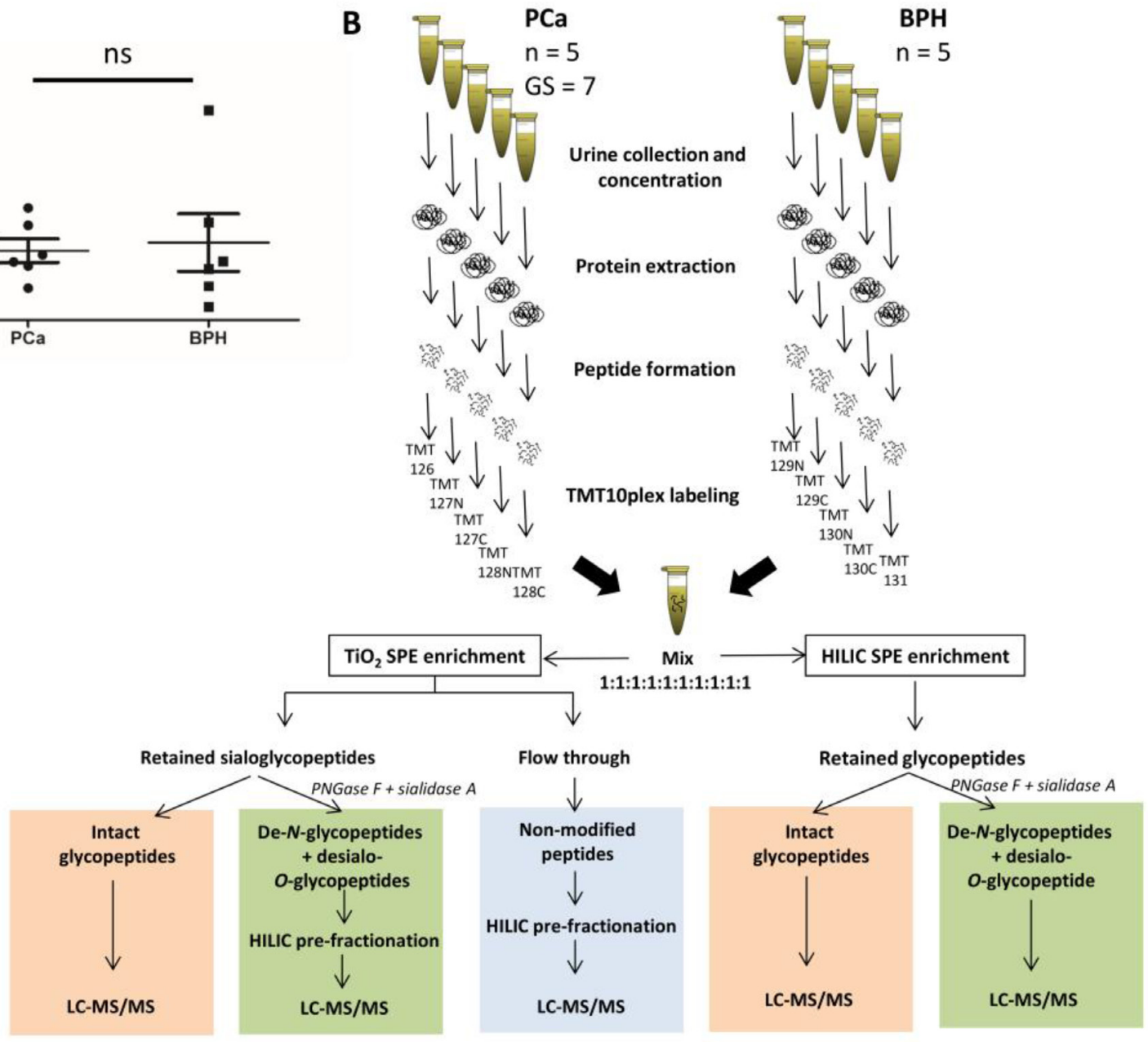

Figure 1: TMT label-assisted quantitative glycoproteomics of urinary glycoprotein from PCa and BPH patients. (A) The serum PSA levels of PCa $(n=6)$ and $\mathrm{BPH}(n=6)$ patients showed no statistical difference ( $p>0.05$, unpaired two tailed $t$-test). (B) Overview of the quantitative glycoproteomics workflow employed in this study. Peptides were generated from extracted urinary proteins from each patient, labelled with isobaric TMT tags and mixed 1:1 (w:w). The glycopeptides were selectively enriched using either $\mathrm{TiO}_{2}$ or HILIC SPE and the resulting fractions were either analyzed directly or after simultaneous endo- and exoglycosidase treatment by LCMS/MS. Former $N$-glycosylated peptides generated by PNGase F (referred to as de- $N$-glycosylated peptides) and desialo- $O$-glycosylated peptides generated by sialidase and non-modified peptides were pre-fractionated using off-line HILIC HPLC; the resulting fractions were analyzed by LC-MS/MS. Different information was obtained from the analysis of intact glycopeptides (red), de- $N$-glycopeptides (green) and non-modified peptides (blue). 
and $\mathrm{TiO}_{2}$ SPE is highly beneficial to increase the coverage of the urinary $N$ - and $O$-glycoproteome.

\section{HILIC HPLC pre-fractionation enhances the coverage of the urinary glycoproteome}

In attempts to reach an even greater coverage of the urinary glycoproteome, off-line HILIC HPLC was implemented in the workflow to pre-fractionate the $\mathrm{TiO}_{2}$ SPE retained glycopeptide fraction. Endo- (PNGase F) and exo- (broad specificity sialidase) glycosidase treatments were also introduced to render the HILIC peptide fractions more amendable to LC-MS/MS detection; it is commonly known that such de- $N$-glycosylated and desialo- $O$-glycopeptides are easier to identify than their native counterparts, albeit with less structural information obtained [33, 34]. Interesting, the de- $N$ glycosylated peptides eluted early in the HILIC HPLC gradient and were efficiently separated from the highly retained desialo- $O$-glycopeptides (Figure 2A). When combined with Orbitrap Q-Exactive HF HCD-MS/MS detection, the HILIC HPLC pre-fractionation facilitated an unprecedented coverage of the urinary glycoproteome by the identification of a total of 1,217 N-glycosylation sites from $696 \mathrm{~N}$-glycoproteins and the detection of 887 desialo- $O$-glycopeptides from $160 O$-glycoproteins (Figure 2B and 2C and Supplementary Tables 7-8).

In total, 1,310 N-glycosylation sites were identified by combining the de- $N$-glycosylated peptides enriched by HILIC SPE and $\mathrm{TiO}_{2}$ SPE and pre-fractionated by HILIC HPLC (Supplementary Tables 2, 7). We then compared our coverage of the urinary $\mathrm{N}$-glycosylation sites in $\mathrm{PCa}$ and BPH urine to a SWATH based identification of the $\mathrm{N}$-glycosylation sites reported in normal prostate, nonaggressive, aggressive and metastatic PCa tumor tissues [21]; a substantial overlap of 337 unique glycosylation sites $(25 \%)$ and $321 \mathrm{~N}$-gycoproteins (44\%) was observed (Supplementary Figure 2A-2B). This result indicates that almost half of the glycoproteins expressed in prostate tissues appear to be mirrored in the excreted urine. We then compared our urinary $\mathrm{N}$-glycoproteome coverage to the $\mathrm{N}$-glycoproteome of two PCa cell lines LNCap and PC3 reported by Shah et al. [20]. In total, $134 \mathrm{~N}$-glycoproteins (11\%) were found to be common between our two data sets (Supplementary Figure 2B). Interestingly, the urinary glycoproteins identified in our study had a closer resemblance to the glycoproteome of $\mathrm{PCa}$ tissues than the glycoproteome of the PCa cell lines.

\section{Quantitative comparison of PCa-associated glycan-compositions and lectin blotting analysis}

We compared the relative abundance of all intact $\mathrm{N}$-glycopeptides grouped by glycan class and terminal features from $\mathrm{PCa}$ and $\mathrm{BPH}$ urine. In doing this, no significant differences were observed between $\mathrm{PCa}$ and
$\mathrm{BPH}$ with respect to the overall relative abundance of high mannose, afucosylated/asialylated complex/hybrid $(\mathrm{C} / \mathrm{H})$, fucosylated complex/hybrid $(\mathrm{C} / \mathrm{H}+\mathrm{Fuc})$, sialylated complex/hybrid (C/H+NeuAc), and fucosylated/sialylated complex/hybrid $(\mathrm{C} / \mathrm{H}+\mathrm{Fuc} / \mathrm{Sia})$. However, increased intensity of Fuc-containing intact desialo- $O$-glycopeptides was observed ( $T$-test, $p<0.05$ ) (Supplementary Figure 3).

Comparative lectin blotting was also performed using concanavalin A (Con A), Maackia amurensis lectin (MAL), wheat germ agglutinin (WGA), Aleuria aurantia lectin (AAL) and Ricinus communis agglutinin (RCA) to assess the level of a range of glycoepitopes in $\mathrm{PCa}$ and $\mathrm{BPH}$ urine in an orthogonal manner. After protein normalization, significantly increased levels of AAL reactivity were observed for the $\mathrm{PCa}$ urinary glycoproteome indicating a higher degree of core fucosylation (Figure 3). Slightly higher Con A reactivity was also observed in $\mathrm{PCa}$ relative to $\mathrm{BPH}$ urine, a feature not reflected in the quantitative LC-MS/MS data of high mannose glycopeptides. However, Con A may also crossreact with paucimannosidic and biantennary complex glycoproteins possibly explaining this discrepancy [35]. Based on these observations, we therefore sought to determine whether site-specific glycosylation instead would display a higher potential of discriminating between urine from $\mathrm{PCa}$ and $\mathrm{BPH}$ patients.

\section{Comparative quantitative glycoproteomics to identify unique site-specific glycosylation signatures in PCa urine}

The datasets of de- $N$-glycosylated peptides and desialo- $O$-glycopeptides generated after $\mathrm{TiO}_{2}$ SPEbased glycopeptide enrichment and HILIC HPLC prefractionation as well as the intact $\mathrm{N}$-glycopeptides identified after HILIC SPE and $\mathrm{TIO}_{2}$ SPE-based glycopeptide enrichments was used to quantitatively compare the glycosylation profile of $\mathrm{PCa}$ and $\mathrm{BPH}$ urine using TMT reporter ion intensities. In addition, to assess for altered protein levels, the intensities from the nonmodified peptides ( $\mathrm{TiO}_{2}$ SPE flow-through fraction) were also compared between $\mathrm{PCa}$ and $\mathrm{BPH}$. The ion intensities of all glycopeptides or non-modified peptides were summed, $\log 2$ transformed, and median normalization was applied. One BPH sample showed different outlier behavior when comparing all samples using PCA and was therefore removed. To reveal statistical differences in the abundance of glycopeptides from PCa $(n=5)$ and BPH groups $(n=4)$, the Limma $\mathrm{R}$ package was used [36]. The total number of differentially abundant intact $\mathrm{N}$-glycopeptides and desialo- $O$-glycopeptides, de- $N$ glycosylated peptides and non-modified peptides, are shown in Figure 2D and Supplementary Table 9.

We then performed unsupervised PCA to assess if these glycopeptides and non-modified peptides were able to discriminate $\mathrm{PCa}$ from $\mathrm{BPH}$. Excitingly, all 
differentially abundant peptides, including the intact $N$ and $O$-glycopeptides, de- $N$-glycosylated peptides and nonmodified peptides, were able to almost completely separate the PCa and BPH groups (Supplementary Figure 4A). Using only the non-modified peptides that were significantly changing in abundance, an overlap between PCa and BPH groups was observed. Interestingly, only the differentially abundant intact $N$-glycopeptides and desialo- $O$-glycopeptides separated completely the $\mathrm{PCa}$ and $\mathrm{BPH}$ groups in the PCA. As a complementary data representation style, we performed clustering analysis using Euclidean distance and a heat map to visualize the altered levels of intact $\mathrm{N}$-glycopeptides and desialo- $O$ glycopeptides. Two large clusters of glycopeptides were observed containing 120 over-represented glycopeptides and 106 under-represented glycopeptides in PCa compared to BPH (Supplementary Figure 4B). These clusters perfectly separated the PCa samples from the BPH samples. These results showed that the urinary

glycoproteome provided better discrimination between the PCa and BPH groups than the non-modified peptides.

Parallel reaction monitoring (PRM), a targeted proteomics strategy [37], was performed to: 1) confirm the levels of some intact glycopeptides in PCa urine; 2) increase the number of peptide-spectrum matches (PSM) for the individual intact glycopeptides to improve the identification confidence and 3 ) improve the quantification accuracy and ion statistics of intact glycopeptides with aberrant levels in the PCa urinary glycoproteome.

The intact $N$-glycopeptide SVVAPATDG GLNLTSTFLR displaying the triantennary and corefucosylated sialoglycoform $\operatorname{HexNAc}(5) \operatorname{Hex}(6) \mathrm{Fuc}(1)$ $\mathrm{NeuAc}(3)$ from prostaglandin-H2 D-isomerase (PTGDS) was present in 29 PRM-MS/MS spectra within the retention time 31.2-32.9 $\mathrm{min}$. The intact $O$-glycopeptide DLCNFNEQLENGGTSLSEK carrying the glycoform HexNAc(3)Hex(1)Fuc(1) from CD59 glycoprotein (CD59) was present in 24 PRM-MS/MS spectra within

B

A

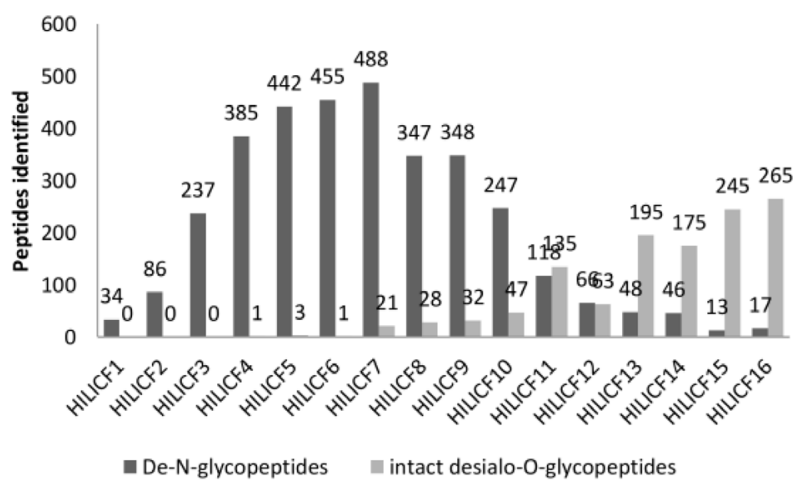

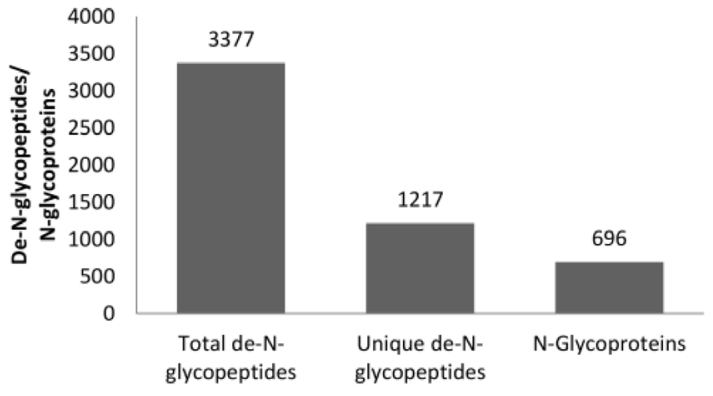
glycopeptide glycopeptides
C

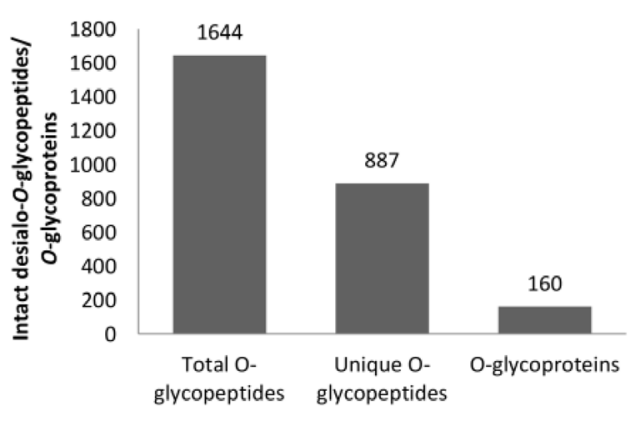

D

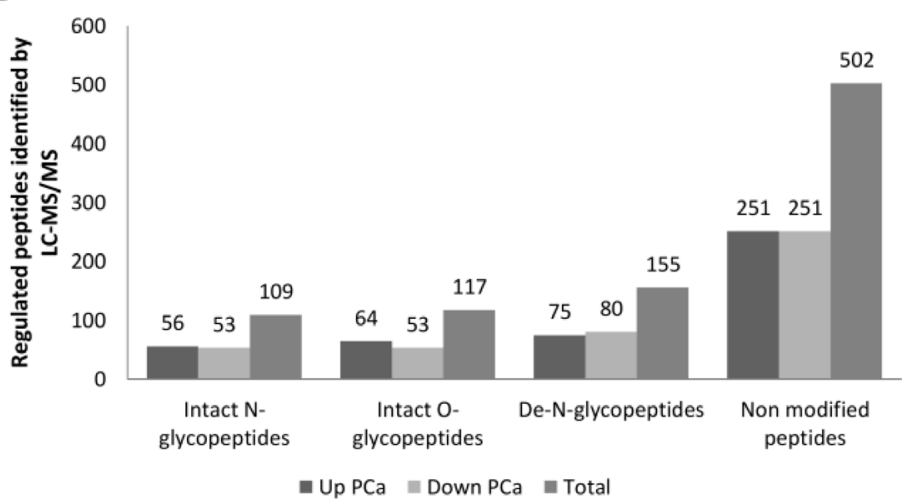

Figure 2: Deep coverage of the urinary $N$ - and $O$-glycoproteome using HILIC HPLC pre-fractionation reveals quantitative glycoproteome differences in PCa and BPH. (A) Distribution of de- $N$-glycopeptides and intact desialo- $O$ glycopeptides identified across the fractions arising from the HILIC HPLC pre-fractionation of $\mathrm{TiO}_{2}$ SPE enriched peptides of urinary proteins. (B) Total and unique de- $N$-glycopeptides/ $N$-glycoproteins and (C) intact desialo- $O$-glycopeptides/O-glycoproteins after HILIC HPLC pre-fractionation. (D) Overview of the differentially abundant intact $N$-glycopeptides (from TiO and HILIC SPE enrichment), desialo- $O$-glycopeptides, de- $N$-glycosylated peptides and non-modified peptides identified in the glycoproteome of PCa relative to BHP urine. 
the retention time $22.8-24.9 \mathrm{~min}$. In comparison, each of these two glycopeptides were only identified from two acquired MS/MS spectra in a data-dependent acquisition (DDA) mode (Supplementary Tables 4 and 6). The TMT reporter ion intensities from the identified spectra of each glycopeptide were summed and normalized to the sum of all TMT reporter ion intensities from each TMT10plex channel during the entire LC-MS/MS run. Statistical differences were assessed by conventional $t$-test analyses. The increased levels of the HexNAc(5)Hex(6)Fuc(1) NeuAc(3) $N$-glycopeptide from PTGDS and decreased levels of the HexNAc(3)Hex(1)Fuc(1) $O$-glycopeptide
A
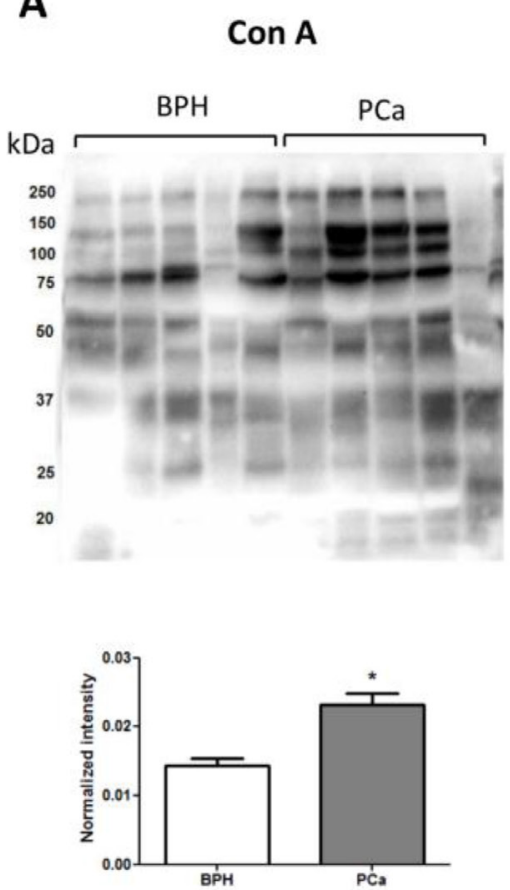

D
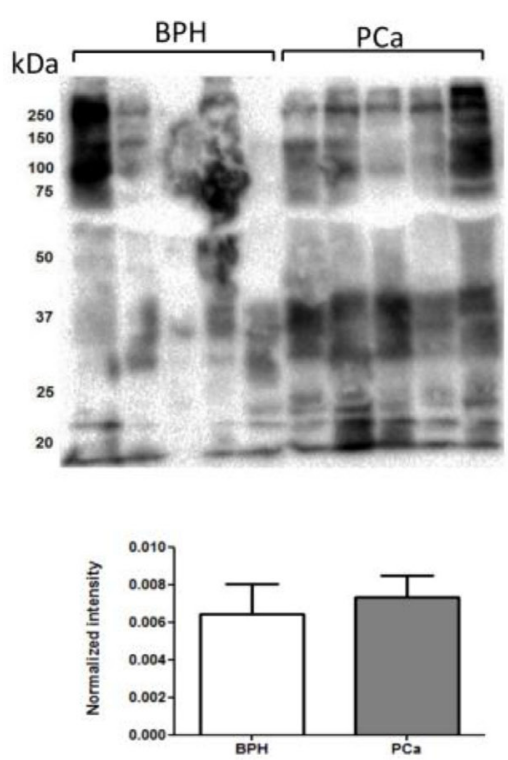

B
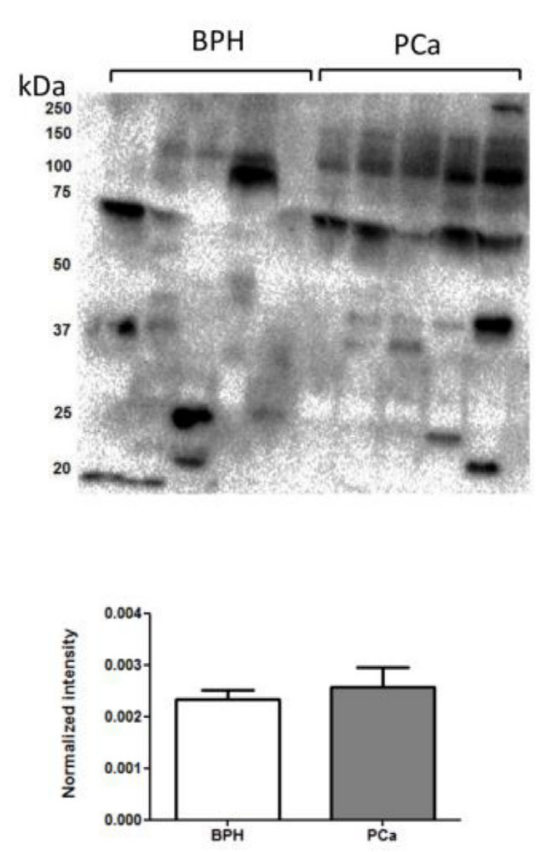

E
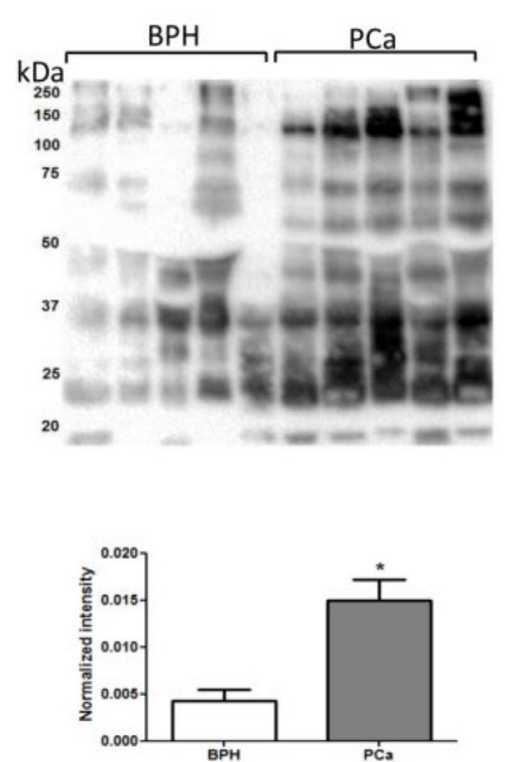

C
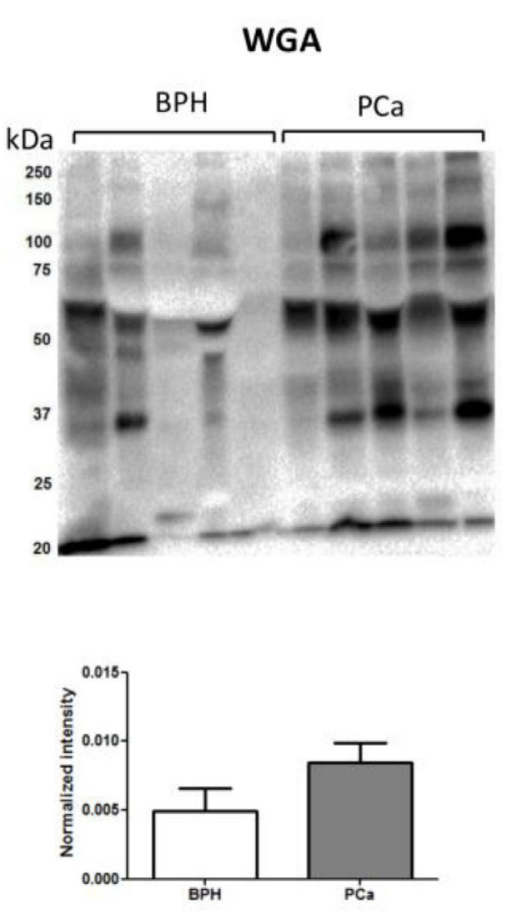

F Coomassie Blue
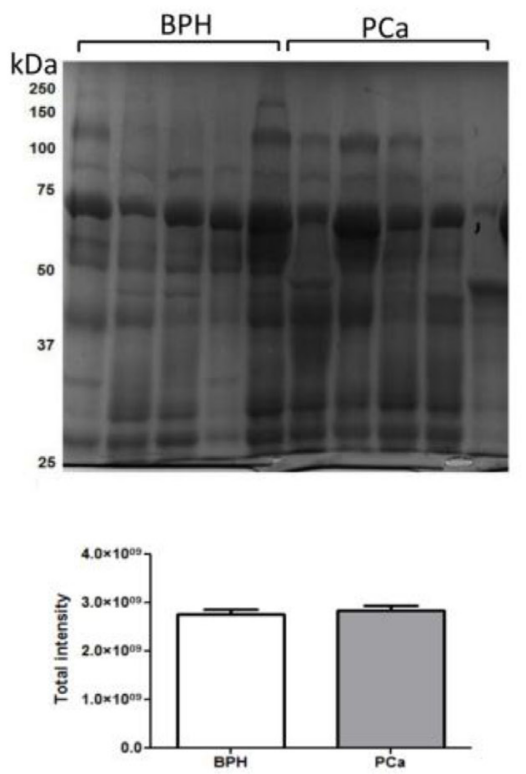

Figure 3: Lectin blotting analysis of PCa and BPH urine. Proteins from PCa and BPH urine (20 ug) were separated on SDSPAGE gels, transferred to PVDF membranes and blotted against Con A (A), MALII (B), WGA (C), RCA (D), AAL (E) lectins. The intensity of each lane after lectin blotting was normalized by the intensity of the respective sample stained by Coomassie (F). 
from CD59 in PCa compared to BPH urine was confirmed (Supplementary Figure 5). Example of annotated PRMMS/MS spectra of these two intact $N$ - and $O$-glycopeptides are shown in Supplementary Figure 6. Importantly, seven non-modified peptides from CD59 and eight non-modified peptides from PTGDS were identified. Most of these non-modified peptides were unaltered in abundance when comparing between the PCa and $\mathrm{BPH}$ urine (Supplementary Table 10). This indicates that the expression levels of these two glycoproteins are likely not altered in $\mathrm{PCa}$, but that the glycosylation of them instead is the molecular feature undergoing regulation.

\section{Intact $N$-glycopeptide marker panel for PCa diagnosis}

To provide a panel of confidently characterized PCa-associated intact glycopeptides, we selected only intact $N$-glycopeptides with significant changes in abundance, whose glycosylation sites were also identified in the de- $N$-glycosylated peptide fractions and whose glycan compositions were commonly known human serum glycoforms reported in UniCarbKB [38]. Besides, we considered only intact glycopeptides displaying fold changes greater than 1.3 or less than 0.77 when comparing PCa to BPH urine. A total of 56 intact $N$-glycopeptides matched these criteria (Table 1). Information of the relative levels of their corresponding glycoproteins was obtained using quantitative LC-MS/MS data of the nonmodified peptide fraction (Supplementary Table 10).

Table 1 shows site-specific glycoforms that are more/less abundant in PCa independently of the protein level. For example, protein AMBP (AMBP) was clearly more abundant at the protein level (as detected by ten nonmodified peptides with increased levels, Supplementary Table 9) and site-specific glycan regulation was observed by the increased relative abundance of three intact glycopeptides covering two $N$-glycosylation sites in PCa urine (Table 1). On the other hand, apolipoprotein $\mathrm{D}$ (APOD) was less abundant in PCa (two non-modified peptides with decreased levels, Supplementary Table 9), but increased levels of site-specific glycosylation (i.e. HexNAc(7)Hex(6)) were observed. In contrast, LTF was found to be both less abundant at the protein level (six under-represented non-modified peptides in $\mathrm{PCa}$ ) and with respect to the $N$-glycosylation site occupancy as evaluated by the under-representation of the de- $N$-glycosylated peptide TAGWNIPMGLLFDQTGSCK and the sitespecific hybrid glycoform HexNAc(4)Hex(7)NeuAc(1) in $\mathrm{PCa}$. Most of the glycoproteins showed no changes at the protein level, but were aberrantly changing with respect to their site-specific glycosylation levels e.g. CLU, LOX, SERPINA4, WFDC2, LAIR1, PIK3IP1 (Table 1). This indicates that the glycosylation machinery, and not the protein translation and secretion, of the cells producing these cancer-associated glycoforms is significantly impacted by the malignant processes associated with PCa.

Some glycopeptides of the urinary glycoproteome were putatively identified with terminal NeuGc. Although being a non-human type of sialic acid, NeuGc may, however, be a component of human glycoproteins arising from exogenous building blocks in particular in glycoproteins of cancer cell origin [39]. These putative NeuGc-containing glycopeptides were manually checked for the presence of the corresponding oxonium ions i.e. $\mathrm{m} / \mathrm{z} 308 / 290$ in the corresponding HCD-MS/MS spectra. All of the glycopeptides showed diagnostic ions for NeuAc $(m / z$ 274/290) instead of NeuGc. The molecular mass of the compositions $\operatorname{HexNAc}(5) \mathrm{Hex}(6) \mathrm{Fuc}(1) \mathrm{NeuAc}(2)$ NeuGc(1), HexNAc(5)Hex(6)Fuc(1)NeuAc(1)NeuGc(1), HexNAc(5)Hex(6)Fuc(1)NeuAc(2)NeuGc(1), HexNAc(4) Hex(5)Fuc(1)NeuAc(1)NeuGc(1) are identical to the mass of HexNAc(5)Hex(7)NeuAc(3), HexNAc(5)Hex(7) NeuAc(2), HexNAc(5)Hex(7)NeuAc(3), HexNAc(4) $\mathrm{Hex}(6) \mathrm{NeuAc}(2)$, respectively. As verified by manual annotation, the NeuAc-containing glycoforms were found to be the correct glycan composition in all of these cases, Table 1. Besides, the composition HexNAc(4)Hex(5) NeuGc(1) was found to be incorrectly identified due to an concomitant oxidation of the peptide. In fact, the correct composition was HexNAc(4)Hex(5)NeuAc(1).

PCA was performed using a panel of 56 intact $N$-glycopeptides identified with high confidence. Complete segregation was observed between $\mathrm{PCa}$ and $\mathrm{BPH}$ (Figure 4A). Interestingly, both the abundance of the glycosylation sites (as measured by the de- $N$-glycosylated peptides) and proteins (measured by the non-modified peptides) from the glycoproteins that were present at different levels in $\mathrm{PCa}$ vs BHP were not able to discriminate between the two diseases (Figure 4B-4C). These results indicate that most $\mathrm{PCa}$-specific glyco-features are not due to quantitative changes in the protein or site occupancy level, but arise from altered abundance of specific glycoforms of the individual urinary glycoproteins from the $\mathrm{PCa}$ patients.

The PCa-specific panel of 56 intact $N$-glycopeptide was also visualized by a heat map. Unsupervised clustering was able to accurately separate the PCa and BPH donors groups (Figure 4D).

The $N$-glycopeptide panel was also evaluated by ROC curve analysis. The AUC was calculated using combinations of 3, 5, 10, 20, 28 and 56 selected $N$-glycopeptides within the entire glycopeptide panel (56 $N$-glycopeptides). Using 20,28 or 56 intact $N$-glycopeptides, an AUC of 1 was obtained demonstrating high specificity and sensitivity of these urinary glycopeptides in the discrimination between the PCa patients from the BHP patients (Figure 4E).

The relationship between the glycoproteins that carried aberrant $N$-glycosylation in PCa relative to BHP was explored in a protein-protein network analysis to search for over- 
Table 1: Differentially abundant intact $N$-glycopeptides identified in PCa and BPH urine $(\mathrm{PCa}=5, \mathrm{BPH}=4$, limma test, $q<0.25$ )

\begin{tabular}{|c|c|c|c|c|c|c|c|c|c|c|c|c|c|}
\hline \multirow{3}{*}{$\begin{array}{l}\text { UniProtKB } \\
\text { ID }\end{array}$} & \multicolumn{2}{|c|}{ Protein ID } & \multicolumn{7}{|c|}{ Intact N-glycopeptides } & \multicolumn{2}{|c|}{ de-N-gycosylated glycosylated peptides } & \multicolumn{2}{|c|}{$\begin{array}{l}\text { Non-modified } \\
\text { peptides }\end{array}$} \\
\hline & \multirow[b]{2}{*}{ Gene } & \multirow[b]{2}{*}{ Protein } & \multicolumn{4}{|c|}{ N-glycan composition } & \multirow[b]{2}{*}{$q$-value } & \multirow{2}{*}{$\begin{array}{l}\text { Ratio* } \\
\text { PCa/ } \\
\text { BPH }\end{array}$} & \multirow[b]{2}{*}{ Direction } & \multirow[b]{2}{*}{ N-Glycosylation site (de) } & \multirow{2}{*}{$\begin{array}{l}\text { Ratio* } \\
\text { PCa/ } \\
\text { BPH }\end{array}$} & \multirow[b]{2}{*}{$\begin{array}{c}\# \\
\text { peptides }\end{array}$} & \multirow{2}{*}{$\begin{array}{c}\text { Av. } \\
\text { ratio* } \\
\text { PCa/ } \\
\text { BPH }\end{array}$} \\
\hline & & & HexNAc & Hex & Fuc & NeuAc & & & & & & & \\
\hline P01042 & $K N G 1$ & Kininogen-1 & 6 & 7 & 1 & 4 & 0.22 & 0.47 & $\begin{array}{l}\text { Down } \\
\text { PCa }\end{array}$ & LNAENN(de)ATFYFK & 1.10 & 20 & 1.7 \\
\hline P01857 & $I G H G I$ & $\begin{array}{l}\text { Immunoglobulin } \\
\text { heavy constant } \\
\text { gamma } 1\end{array}$ & 4 & 5 & 1 & 1 & 0.20 & 2.18 & Up PCa & EEQYN(de)STYR & 1.15 & 10 & 0.8 \\
\hline P01859 & $I G H G 2$ & $\begin{array}{l}\text { Immunoglobulin } \\
\text { heavy constant } \\
\text { gamma } 2\end{array}$ & 4 & 4 & 1 & & 0.20 & 0.49 & $\begin{array}{l}\text { Down } \\
\text { PCa }\end{array}$ & EEQFN(de)STFR & 0.74 & 3 & 0.5 \\
\hline \multirow[t]{2}{*}{ P01877 } & IGHA2 & $\begin{array}{l}\text { Immunoglobulin } \\
\text { heavy constant } \\
\quad \text { alpha } 2\end{array}$ & 5 & 3 & 1 & & 0.20 & 1.58 & Up PCa & TPLTAN(de)ITK & 0.68 & 2 & 1.3 \\
\hline & & & 4 & 5 & & 1 & 0.23 & 1.60 & Up PCa & $\begin{array}{l}\text { YFYN(de)GTSMACETF } \\
\text { QYGGCMGNGNNFVTEK }\end{array}$ & 1.90 & & \\
\hline \multirow[t]{2}{*}{ P02760 } & $A M B P$ & Protein AMBP & 5 & 6 & & & 0.23 & 2.47 & Up PCa & $\begin{array}{l}\text { YFYN(de)GTSMACETF } \\
\text { QYGGCMGNGNNFVTEK }\end{array}$ & 1.90 & 24 & 2.4 \\
\hline & & & 6 & 6 & 1 & & 0.20 & 3.32 & Up PCa & $\begin{array}{l}\text { YFYN(de)GTSMACETF } \\
\text { QYGGCMGNGNNFVTEK }\end{array}$ & 1.90 & & \\
\hline \multirow{2}{*}{ P02765 } & \multirow{2}{*}{$A H S G$} & \multirow{2}{*}{$\begin{array}{l}\text { Alpha-2-HS- } \\
\text { glycoprotein }\end{array}$} & 4 & 5 & & 2 & 0.20 & 0.33 & $\begin{array}{l}\text { Down } \\
\text { PCa }\end{array}$ & $\begin{array}{l}\text { AALAAFNAQNN(de) } \\
\text { GSNFQLEEISR }\end{array}$ & 1.38 & \multirow{2}{*}{8} & \multirow{2}{*}{1.7} \\
\hline & & & 4 & 6 & 1 & & 0.20 & 2.56 & Up PCa & $\begin{array}{l}\text { AALAAFNAQNN(de) } \\
\text { GSNFQLEEISR }\end{array}$ & 1.38 & & \\
\hline P02788 & $L T F$ & Lactotransferrin & 4 & 7 & & 1 & 0.23 & 0.51 & $\begin{array}{l}\text { Down } \\
\text { PCa }\end{array}$ & $\begin{array}{l}\text { TAGWNIPMGLLFN } \\
\text { (de)QTGSCK }\end{array}$ & 0.52 & 23 & 0.7 \\
\hline P05090 & $A P O D$ & Apolipoprotein D & 7 & 6 & & & 0.24 & 1.40 & Up PCa & $\begin{array}{l}\text { ADGTVNQIEGEATPVN } \\
\text { (de)LTEPAK }\end{array}$ & 2.78 & 6 & 0.6 \\
\hline \multirow[t]{6}{*}{ P05155 } & \multirow[t]{6}{*}{ SERPINGI } & \multirow[t]{6}{*}{$\begin{array}{l}\text { Plasma protease } \\
\text { C1 inhibitor }\end{array}$} & 4 & 5 & & 2 & 0.20 & 2.76 & Up PCa & $\begin{array}{c}\text { ASSNPN(de) } \\
\text { ATSSSSQDPESLQDR }\end{array}$ & 0.92 & 5 & 1.5 \\
\hline & & & 5 & 7 & & 3 & 0.20 & 0.35 & $\begin{array}{l}\text { Down } \\
\text { PCa }\end{array}$ & $\begin{array}{l}\text { FALLMTNCYATPSSN } \\
\text { (de)ATDPLK }\end{array}$ & 0.87 & & \\
\hline & & & 4 & 6 & & 1 & 0.20 & 0.14 & $\begin{array}{l}\text { Down } \\
\text { PCa }\end{array}$ & $\begin{array}{l}\text { FALLMTNCYATPSSN } \\
\text { (de)ATDPLK }\end{array}$ & 0.87 & & \\
\hline & & & 5 & 4 & & 1 & 0.20 & 0.30 & $\begin{array}{l}\text { Down } \\
\text { PCa }\end{array}$ & $\begin{array}{l}\text { FALLMTNCYATPSSN } \\
\text { (de)ATDPLK }\end{array}$ & 0.87 & & \\
\hline & & & 6 & 7 & & 3 & 0.23 & 0.46 & $\begin{array}{l}\text { Down } \\
\text { PCa }\end{array}$ & $\begin{array}{l}\text { FALLMTNCYATPSSN } \\
\text { (de)ATDPLK }\end{array}$ & 0.87 & & \\
\hline & & & 6 & 7 & & 2 & 0.25 & 0.54 & $\begin{array}{l}\text { Down } \\
\text { PCa }\end{array}$ & $\begin{array}{l}\text { FALLMTNCYATPSSN } \\
\text { (de)ATDPLK }\end{array}$ & 0.87 & & \\
\hline \multirow[t]{6}{*}{ P07911 } & \multirow[t]{6}{*}{$U M O D$} & Uromodulin & 6 & 5 & 1 & 3 & 0.20 & 0.58 & $\begin{array}{l}\text { Down } \\
\text { PCa }\end{array}$ & $\begin{array}{l}\text { FALLMTNCYATPSSN } \\
\text { (de)ATDPLK }\end{array}$ & 0.87 & 29 & 1.4 \\
\hline & & & 9 & 4 & 1 & & 0.20 & 0.76 & $\begin{array}{l}\text { Down } \\
\text { PCa }\end{array}$ & $\begin{array}{l}\text { FALLMTNCYATPSSN } \\
\text { de)ATDPLK }\end{array}$ & 0.87 & & \\
\hline & & & 7 & 6 & & & 0.20 & 1.55 & Up PCa & $\begin{array}{l}\text { FALLMTNCYATPSSN } \\
\text { (de)ATDPLK }\end{array}$ & 0.87 & & \\
\hline & & & 5 & 6 & & 2 & 0.23 & 0.59 & $\begin{array}{l}\text { Down } \\
\text { PCa }\end{array}$ & $\begin{array}{c}\text { CNTAAPMWLN } \\
\text { (de)GTHPSSDEGIVSR }\end{array}$ & 1.03 & & \\
\hline & & & 5 & 6 & 1 & 3 & 0.20 & 0.19 & $\begin{array}{l}\text { Down } \\
\text { PCa }\end{array}$ & $\begin{array}{l}\text { QDFN(de) } \\
\text { ITDISLLEHR }\end{array}$ & 1.16 & & \\
\hline & & & 6 & 7 & & 4 & 0.20 & 0.48 & $\begin{array}{l}\text { Down } \\
\mathrm{PCa}\end{array}$ & $\begin{array}{l}\text { QDFN(de) } \\
\text { ITDISLLEHR }\end{array}$ & 1.16 & & \\
\hline P08185 & SERPINA6 & $\begin{array}{l}\text { Corticosteroid- } \\
\text { binding globulin }\end{array}$ & 4 & 5 & & 2 & 0.20 & 0.32 & $\begin{array}{l}\text { Down } \\
\text { PCa }\end{array}$ & $\begin{array}{l}\text { AQLLQGLGFN(de) } \\
\text { LTER }\end{array}$ & 0.67 & & \\
\hline & & & 4 & 5 & 2 & 1 & 0.23 & 1.61 & Up PCa & $\begin{array}{c}\text { LAN(de) } \\
\text { LTQGEDQYYLR }\end{array}$ & 0.80 & & \\
\hline P10909 & $C L U$ & Clusterin & 5 & 6 & & 3 & 0.20 & 3.01 & Up PCa & KEDALN(de)ETR & 1.46 & 6 & 1.6 \\
\hline & & & 4 & 5 & & 2 & 0.23 & 2.46 & Up PCa & EDALN(de)ETR & 1.56 & & \\
\hline
\end{tabular}




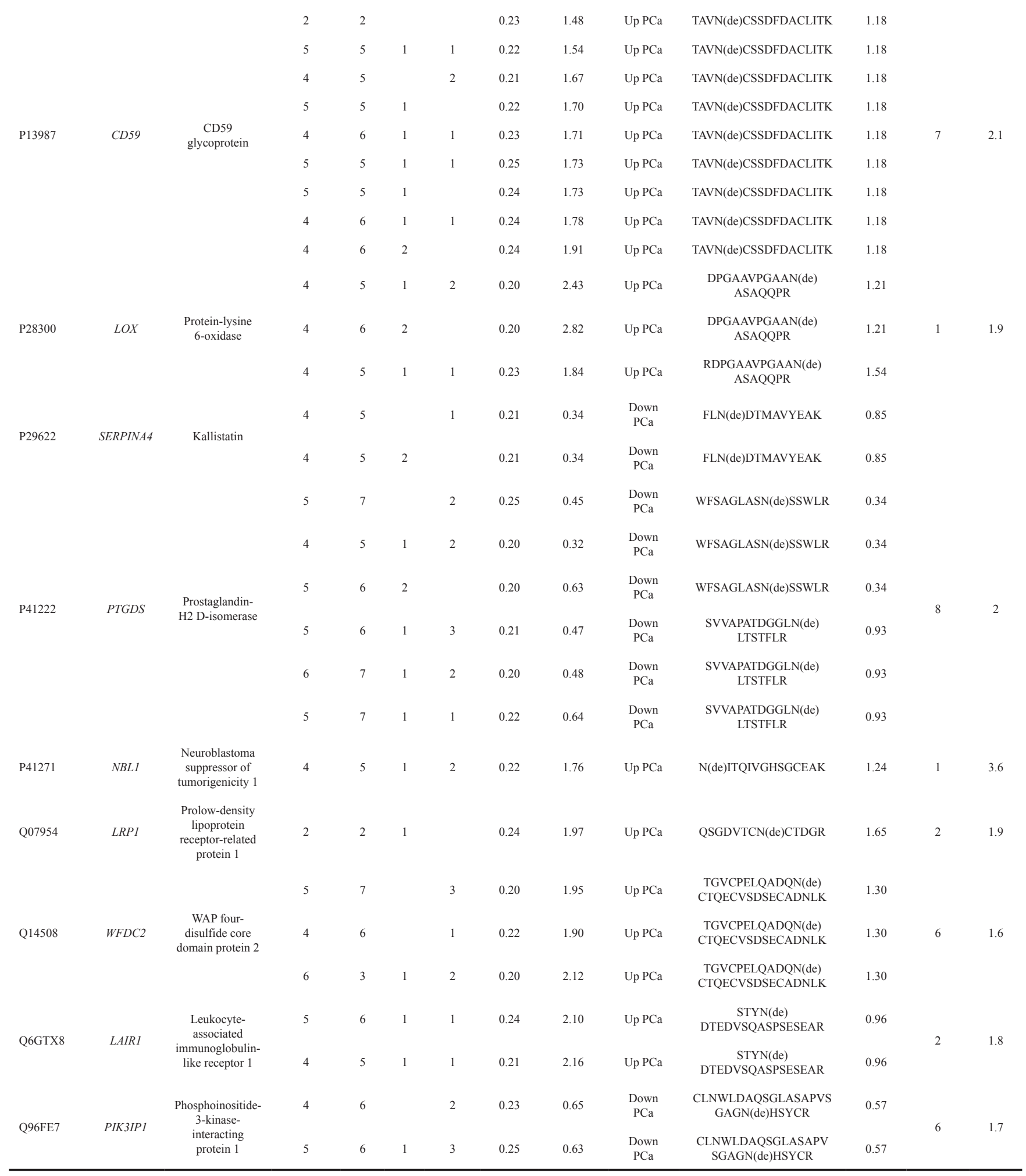

Only intact $N$-glycopeptides detected with significant differences in abundance (ratio PCa/BPH $>1.3$ and $<0.76$ ), carrying a glycan composition reported in UniCarbKB and with the glycosylation site confirmed in the de- $N$-glycosylated peptide fraction are displayed in this table.

"Ratio was calculated by the average of normalized TMT reporter intensities from the PCa $(n=5)$ and BPH $(n=4)$ samples.

represented biological functions and pathways. Significant enrichment of pathways pertaining to the complement and coagulation cascade (KEGG pathway) and a regulation of immune system response (Gene Ontology Biological process) were observed in the network of glycoproteins carrying aberrant glycosylation in PCa (Figure 4F). 
In support of our finding, many of the glycoproteins in our panel were already shown in previous studies to be altered in $\mathrm{PCa}$ or involved in tumor growth and development. For example: AMBP for PCa diagnosis [40], CD59 associated with PCa progression [41-43], CLU as a therapeutic target against PCa [44] and predictor for PCA recurrence [45], and PTGDS was found in increased concentration in urine from $\mathrm{PCa}$ patients [40]. The association of these glycoproteins to $\mathrm{PCa}$ in these previous studies was established based on the protein expression level. In contrast, we show here for the first time, that sitespecific glycan compositions are also altered in this set of glycoproteins in $\mathrm{PCa}$.

\section{DISCUSSION}

In this study, 1,310 de- $N$-glycosylated peptides, 954 intact $N$-glycopeptides and 887 desialylated but otherwise intact $O$-glycopeptides belonging to a total of 788 glycoproteins were identified. This deep coverage should be evaluated in the light of past efforts in this space including a study by Halim et al. [46], which showed the characterization of $58 \mathrm{~N}$ - and $63 \mathrm{O}$-glycopeptides from 53 urinary glycoproteins, Saraswat et al. [47] who reported $51 \mathrm{~N}$-glycosylation sites belonging to 37 glycoproteins from the urinary exosomes and our own past study of urine i.e. Kawahara et al. [27] reporting 472 unique
A

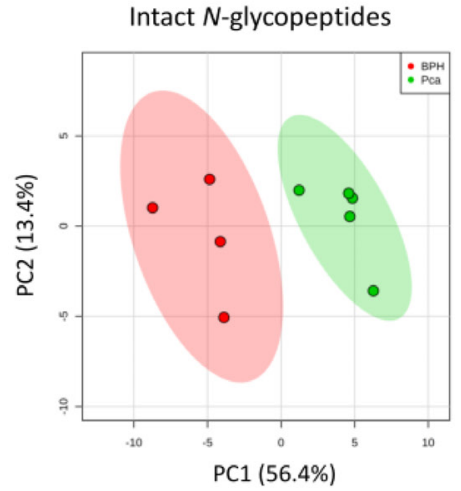

B De- $N$-glycosylated peptides

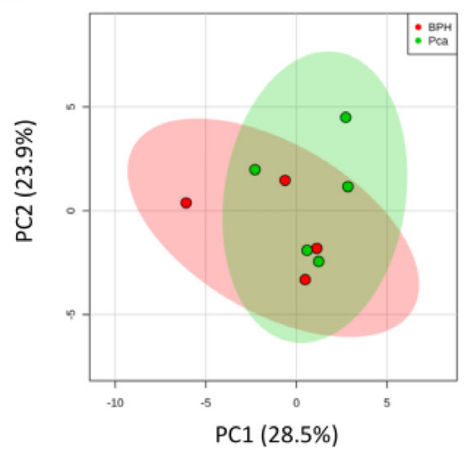

\section{Non-modified peptides}

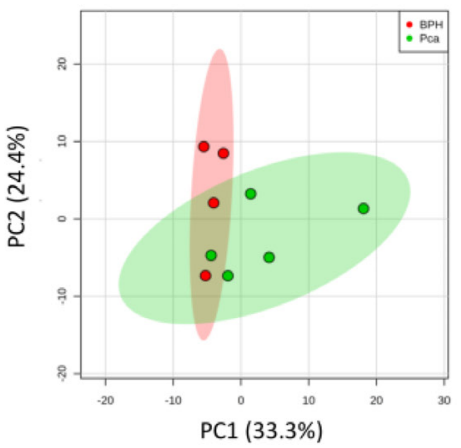

D

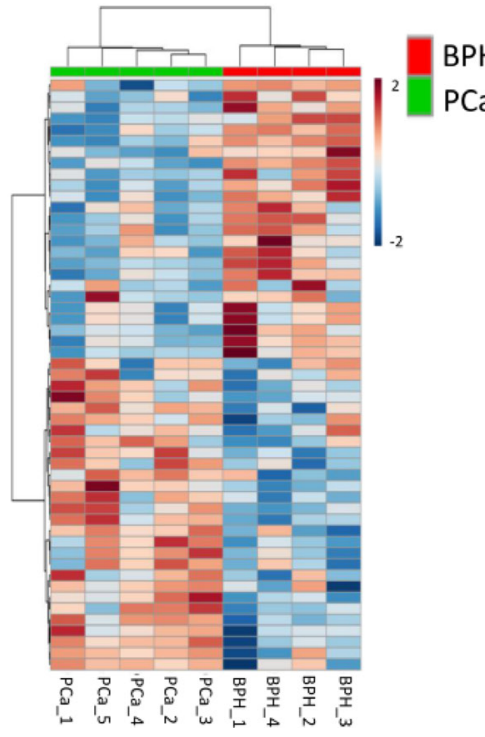

E

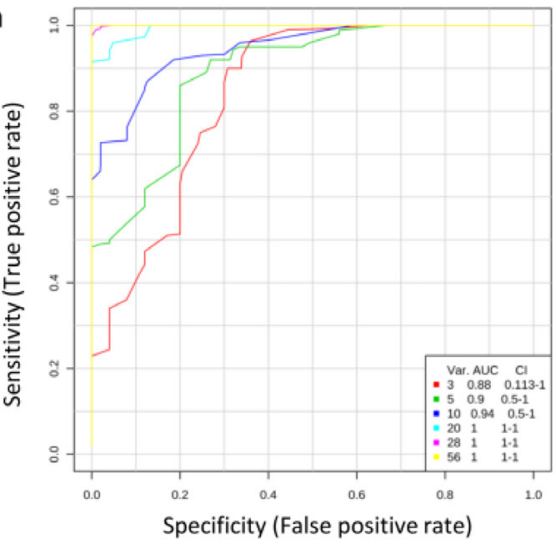

$\mathbf{F}$

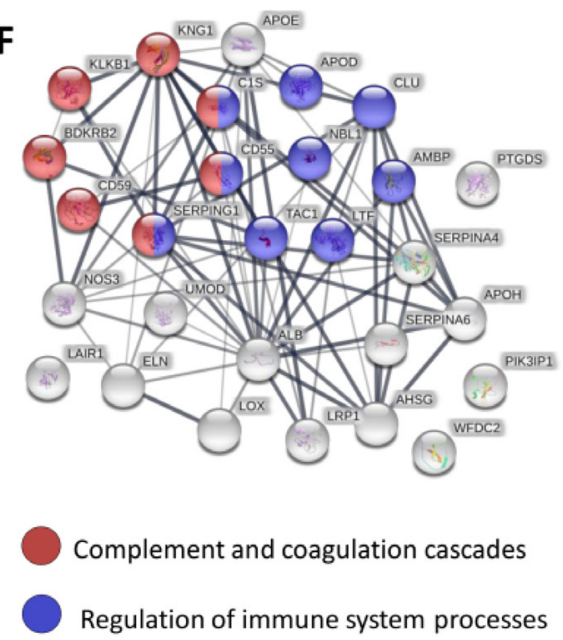

Figure 4: Intact $\boldsymbol{N}$-glycopeptides as candidate biomarkers for PCa detection. (A) Principal component analysis (PCA) using a panel of $56 \mathrm{~N}$-glycopeptides with aberrant levels in PCa relative to BHP (Table 1). (B) PCA using a set of 27 deamidated peptides covering the same glycosylation sites as identified with intact $N$-glycopeptide analysis (Table 1). (C) PCA using a set of non-modified peptides from the glycoproteins that carried the panel of differentially abundant intact $N$-glycopeptides (Table 1). (D) Clustering of intact $N$-glycopeptides displaying altered expression in PCa is shown as a heat map after applying Euclidean distance. (E) ROC curve analysis was performed based on partial least squares discriminant analysis (PLS-DA) using the panel of PCa-associated intact $N$-glycopeptides (Table 1). (F) Network analysis using the list of glycoproteins which carried the differentially abundant intact $N$-glycopeptides (Table 1). Significant enriched KEGG pathway complement and coagulation cascades (FDR < 0.05) and regulation of immune system response (Gene Ontology, FDR $<0.05$ ) are colored in blue and red, respectively. 
$\mathrm{N}$-glycosylation sites covering 256 urinary glycoproteins. Thus, this present study clearly represents the deepest coverage of the $\mathrm{N}$ - and $\mathrm{O}$-glycoproteome of human urine to date.

One of the technical issues associated with urine analysis is the high inter- and intra-individual variability [6], which was previously shown to account for $48 \%$ and $66 \%$ of CV variation, respectively [48]. In addition, the multi-step sample preparation and LC-MS/ MS acquisition are likely sources of technical variation [49]. We took advantage of the available TMT labeling technology, which not only allowed multiplexing of samples to reduce the LC-MS/MS acquisition time, but also minimized the technical variation from the sample handling [49], especially the peptide enrichment and pre-fractionation, while simultaneously facilitating more accurate quantification of glycopeptides and non-modified peptides [50]. Due to the relative low number of biological replicates and high variance between the individuals, our study was limited to a non-stringent threshold of $q<0.25$ for the peptide FDRs to determine differentially abundant glycoproteins in $\mathrm{PCa}$ and $\mathrm{BPH}$ urine. However, by validating the levels of specific intact glycopeptides by PRM-MS/MS we significantly enhanced the confidence in these observations.

An important limitation of the chosen workflow is that, in complex mixtures, co-isolation of multiple precursor ions is the most acknowledged limitation of quantitative proteomics using isobaric labels. This shortcoming reduces the precision and accuracy of the quantification $[51,52]$. It was demonstrated that due to this interference problem, the actual abundance ratios are typically underestimated [49]. Using precursor intensity fraction (PIF) tool available in MaxQuant [53], we filtered peptides that clearly suffer from co-isolation of other peptide precursor ions.

Glycans facilitate and contribute to many different aspects of tumor progression, including proliferation, invasion, angiogenesis and metastasis [54]. In cancer, protein glycosylation is dynamically regulated due to altered expression of glycan-modifying enzymes [55, 56]. Wang et al. [57] showed high expression of a1,6-fucosyltransferase (FUT8) in tumor tissue from patients with metastatic and aggressive primary $\mathrm{PCa}$ and was positively correlated with $\mathrm{PCa}$ with high Gleason scores. The $\mathrm{N}$-glycosylation of proteins was demonstrated previously to be altered in urine [58], tissues [21] and serum [59] from PCa patients as well as in PCa cell lines [20]. Interestingly, using meta-analysis of publicly available transcriptomic data from different $\mathrm{PCa}$ studies, Barfeld et al. [60] reported a concise 33 gene signature with biological enrichment for protein glycosylation, which discriminates between $\mathrm{PCa}$ and $\mathrm{BPH}$ across multiple transcript detection platforms and sample types. Meany et al. [59] reported that direct analysis of PSA $N$-glycosylation in sera may be able to improve the sub-optimal specificity of PSA as a PCa marker. Altered glycosylation of PSA isolated from PCa serum and/ or seminal plasma relative to PSA glycosylation from controls was repeatedly observed by Tabares et al. [61], Llop et al. [62] and Ohyama et al. [63]. Collectively, these studies clearly support the association of altered of protein glycosylation with PCa. Although glycoproteomics studies have previously been used to explore PCa [20-22], the quantitative information relating to site-specific $N$ - and $O$-glycosylation and the glycan compositions were not reported in those studies.

We demonstrated that differentially abundant glycopeptides discriminate more accurately between $\mathrm{PCa}$ and $\mathrm{BPH}$ groups than differentially abundant nonmodified peptides. Thus, we argue that a selected panel of glycopeptides, but not their corresponding nonglycosylated peptides from the same protein, may serve as candidate biomarkers for $\mathrm{PCa}$ detection. We demonstrated that the malignant processes associated with $\mathrm{PCa}$ are more frequently reflected directly in the glycosylation of proteins as oppose to the aberrations in the expression level or the glycosylation site occupancy of those proteins. Although we were limited to investigating a relative small patient cohort, the potential of intact glycopeptides to stratify patient groups can be explored in follow-up studies using larger cohort of patients once the glycoproteomics technology matures further allowing more streamlined data collection and interpretation of a larger patient cohort.

Among the PCa-associated glycopeptides, we targeted the $\mathrm{N}$-glycosylation of prostaglandin- $\mathrm{H} 2$ D-isomerase (PTGDS) and the $O$-glycosylation of CD59 using PRM analysis. Interestingly, Davalieva et al. [40] and Ahmad et al. [7] showed that these two glycoproteins are over-expressed in the urine of PCa patients. Herein, we complement their observations by reporting that PTGDS and CD59 carry aberrant glycosylation at defined positions in PCa urine.

CD59 is a glycosyl-phosphatidylinositol (GPI)anchored cell membrane glycoprotein that inhibits complement-mediated cell lysis by preventing full assembly of the membrane attack complex (MAC) on host cells, and thus might confer immune resistance to tumor cells [42]. High expression of CD59 protein was associated with higher Gleason scores and higher $\mathrm{pT}$ stages in PCa [41]. It was demonstrated that prostasomes, which are secretory granules produced, stored, and released by the glandular epithelial cells of the prostate, had higher expression of CD59 than those of normal cells [64]. CD59 glycosylation was previously characterized and several roles for the glycans, including spacing and orienting CD59 on the cell surface and protecting the molecule from proteases were proposed based on structural data [65].

Prostaglandin-H2 D-isomerase was identified in human seminal plasma [66]. Prostaglandin D2 (PGD2) and prostaglandin D2 synthase (PTGDS) is involved in the regulation of testis tissue differentiation [67, 68]. 
PGD2, which is synthesized by PTGDS in many organs, has been implicated as a signaling molecule in the mediation or regulation of various biological processes, including tumorigenic process in PCa [69]. It was shown that PTGDS activity is defined by post-translational modifications, and point mutation in a glycosylation site (Asn51) inhibited L-PGDS-induced apoptosis and caspase 3 activity [70]. Interestingly, we identified a significant lower abundance in the Asn51 glycoform HexNAc(4) Hex(5)Fuc(1)NeuAc(2) and HexNAc(5)Hex(6)Fuc(2) in PCa compared to BPH urine (Table 1).

The quantitative analysis of intact glycoproteins opens novel avenues for assessing the dysregulation of glycoproteins in $\mathrm{PCa}$ and tie such information with aberrant glycoprotein function as drivers or passive byproducts of tumour development and progression.

The quantification of specific peptides glycoforms is challenging due to the low ionization efficiency of glycanmodified peptides, as well as the lack of glycopeptides reference spectra. Moreover, multiple glycoforms (microheterogeneity) are detected as separate glycopeptides, thus diminishing the signal intensity for each glycopeptide form. Selected reaction monitoring (SRM) and parallel reaction monitoring (PRM) are currently the leading methods for targeted MS-based quantification of proteins. Recently, SRM was applied to quantify candidate nonmodified peptides biomarkers in expressed prostatic secretions (EPSs) from PCa and control patients [71]. Song et al. [72] applied MRM to quantify intact glycopeptides in depleted human blood serum using the glycans oxonium ions as transitions. However, to this date quantification of intact glycopeptides using targeted MS approaches is still poorly explored. We showed PRM is a useful approach to quantify intact glycopeptides. The number of MS/MS spectra recorder increased beyond a 20 fold by using PRM for targeted glycopeptide analysis, improving the accuracy of the identification and quantitation. Integrating this approach with synthetic glycopeptides for normalization and absolute quantification would enhance value and utility of the PRM-MS/MS workflow even further.

We found the complement and coagulation cascades to be over-represented pathways in the set of urinary glycoproteins carrying differentially abundant sitespecific glycoforms. Interestingly, the same pathway was observed to be enriched in the meta-analysis from Barfeld et al. [60] which contained differentially expressed genes between localized $\mathrm{PCa}$ and benign prostate tissue, thus demonstrating that biological processes occurring in prostatic tissues may be reflected in urine.

Different coagulation disorders were reported during prostatic carcinoma evolution [73]. The most frequent coagulation complication is the disseminated intravascular coagulation (DIC), which is a result of the release of pro-coagulant substances, such as tissue factors, into the bloodstream [74]. This coagulation disorder was reported in many patients with $\mathrm{PCa}$ [75-77]. We identified seven glycoproteins displaying aberrant sitespecific glycosylation that are related to complement and coagulation cascade pathway. The set of differentially abundant site-specific glycoforms belonging to these glycoproteins can be explored as candidate biomarkers for coagulation disorders that may be present during $\mathrm{PCa}$ progression.

Additionally, recent reports suggest that the complement elements can promote tumor growth in the context of chronic inflammation, immunosuppression, angiogenesis, and cancer cell signaling [78-80]. Manning et al. also showed that human PSA, via its chymotrypsinlike serine protease activity, can modulate the complement system through degradation of $\mathrm{iC} 3 \mathrm{~b}$ to produce new C3 degradation fragments and through degradation of the complement protein $\mathrm{C} 5$, thereby inactivating the complement cascade [81].

In summary, this study reports several innovative approaches advancing our pursuit of reliable and sensitive urinary biomarker for PCa discovery and stratification from $\mathrm{BPH}$ by 1) providing the largest coverage of the urinary $\mathrm{N}$ - and $\mathrm{O}$-glycoproteome to date, 2) providing a panel of $56 \mathrm{~N}$-glycopeptides derived from aberrantly expressed glycoproteins in PCa urine representing an exciting collection of potential candidate biomarkers for discrimination of $\mathrm{PCa}$ from $\mathrm{BHP}$ and by 3) achieving confident structural characterization including the peptide carrier identity, site annotation, and glycan composition as well as quantitative validation of the panel of glycopeptide candidate markers by the application of innovative LCMS/MS and PRM approaches of intact glycopetides. This study opens new promising avenues for using urinary glycoproteins, a hitherto largely untapped resource, as candidate biomarkers for PCa detection.

\section{MATERIALS AND METHODS}

\section{Urine collection, protein extraction and peptide generation}

The study was approved by the ethics review board of the Instituto do Câncer do Estado de São Paulo (ICESP), under the protocol $n^{0} 784 / 15$. Written informed consents were obtained from all participants. The methods were performed in accordance with the approved guidelines and regulations.

The first voided urine after prostate biopsy was collected prospectively from men who were admitted for prostate biopsies based on serum PSA levels $\geq 4.0 \mathrm{ng} / \mathrm{ml}$ and/or abnormal DRE. All men had received study information, and they had signed the informed consent. In this study, a total of 12 subjects were included, of whom 6 were validated to have PCa based on biopsy examination by a trained pathologist. The men were asked to void, and the first $\sim 30 \mathrm{ml}$ of urine was collected and immediately cooled on ice. The samples were centrifuged at 3,000 $\times \mathrm{g}$ 
for $10 \mathrm{~min}$ at $4^{\circ} \mathrm{C}$. The cleared supernatant $(\sim 2-20 \mathrm{ml})$ was further filtered using $0.22 \mu \mathrm{m}$ filters (Millipore, Billerica, MA). Two milliliters of filtered urine was then concentrated using $10 \mathrm{kDa}$ cutoff filters (Millipore, Billerica, MA) and stored immediately at $-20^{\circ} \mathrm{C}$ until further use. The total protein amount was determined using Qbit fluorometric quantitation (Thermo).

\section{Protein digestion and desalting}

Proteins $(100 \mu \mathrm{g})$ were reduced by addition of dithiothreitol (DTT) to a final concentration of $10 \mathrm{mM}$ and incubated for $30 \mathrm{~min}$ at $30^{\circ} \mathrm{C}$. Proteins were alkylated prior to digestion by the addition of iodoacetamide (IAA) to a final concentration of $40 \mathrm{mM}$ and incubated for $30 \mathrm{~min}$ in the dark at room temperature. To quench the reaction, DTT was added to a final concentration of $10 \mathrm{mM}$. Porcine trypsin (1:50, w/w, sequence-grade, Promega) was added, and the mixture incubated overnight at $37^{\circ} \mathrm{C}$. The reaction was stopped with the addition of $1 \%$ TFA and the resulting peptides were purified using a primed Oligo R3 reversed phase SPE micro-column and dried [29].

\section{Isobaric peptide labeling with TMT}

Peptides originating from $\sim 100 \mu \mathrm{g}$ protein from each urine sample were dissolved in $100 \mu 100 \mathrm{mM}$ TEAB and labeled individually with TMT-10plex mass tags (Thermo) according to the manufacturer's instructions. Briefly, each TMT10plex tag $(0.8 \mathrm{mg})$ was resuspended with $41 \mu \mathrm{l}$ neat anhydrous acetonitrile and added to each of the peptide samples and the mixture incubated for $1 \mathrm{~h}$ at room temperature after vigorous vortexing for $5 \mathrm{~min}$. To quench the reaction, $8 \mu 15 \%(\mathrm{v} / \mathrm{v})$ hydroxylamine was added per sample followed by $15 \mathrm{~min}$ incubation at room temperature. After TMT labelling, all peptide samples were mixed 1:1 (w:w), divided into two aliquots $(\sim 500 \mu \mathrm{g}$ each) and purified on a primed Oligo R3 reversed phase SPE micro-column.

\section{Glycopeptide enrichment using titanium dioxide $\left(\mathrm{TiO}_{2}\right) \mathrm{SPE}$}

One of the aliquots from the TMT-labeled peptide samples $(\sim 500 \mu \mathrm{g})$ was used for sialoglycopeptide enrichment using $\mathrm{TiO}_{2}$ SPE according to Larsen et al. [28] and Palmisano et al. [29]. Samples were resuspended in $1 \mathrm{ml}$ loading buffer containing $1 \mathrm{M}$ glycolic acid, $80 \%$ acetonitrile (ACN), 5\% TFA. The samples were incubated with $\mathrm{TiO}_{2}$ beads (GL Sciences, Japan, $5 \mu \mathrm{m}$ ) using a total of $0.6 \mathrm{mg} \mathrm{TiO}_{2}$ beads per $100 \mu \mathrm{g}$ peptides and shaken at room temperature for $15 \mathrm{~min}$. The suspension was centrifuged at $1,000 \times \mathrm{g}$ for $1 \mathrm{~min}$ and the supernatant transferred to another vial with a fresh batch of $\mathrm{TiO}_{2}$ beads (containing half the amount of $\mathrm{TiO}_{2}$ beads as initially used) and shaken at room temperature for $15 \mathrm{~min}$. The two batches of $\mathrm{TiO}_{2}$ beads were washed with $100 \mu 1$ loading buffer and centrifuged at $1,000 \times \mathrm{g}$ for $1 \mathrm{~min}$. The supernatant was discarded and the beads washed with $100 \mu \mathrm{l}$ washing buffer 1 containing $80 \% \mathrm{ACN}$ in $1 \%$ aqueous TFA (both $\mathrm{v} / \mathrm{v}$ ) and centrifuged at 1,000 $\times \mathrm{g}$ for $1 \mathrm{~min}$. The supernatant was discarded and the beads were washed with $100 \mu \mathrm{l}$ washing buffer 2 containing 20\% $\mathrm{ACN}$ in $0.2 \%$ aqueous TFA (both $\mathrm{v} / \mathrm{v}$ ) and centrifuged at $1,000 \times \mathrm{g}$ for $1 \mathrm{~min}$. The supernatant was again discarded and the beads were dried in a vacuum centrifuge for $5 \mathrm{~min}$. The bound peptides were eluted by resuspending the $\mathrm{TiO}_{2}$ beads in $100 \mu$ l elution buffer containing $1 \%(\mathrm{v} / \mathrm{v})$ aqueous ammonium hydroxide and by vortexing the beads for $15 \mathrm{~min}$. The mixtures were then centrifuged at $1,000 \times \mathrm{g}$ for $1 \mathrm{~min}$, the peptide-containing supernatant transferred to separate tubes and the eluted peptides were aliquoted and dried by vacuum centrifugation. This produced an enriched sialoglycopeptide fraction.

\section{Glycopeptide enrichment using hydrophilic interaction liquid chromatography (HILIC) SPE}

The second aliquot of TMT-labeled urinary peptides $(\sim 500 \mu \mathrm{g})$ was reconstituted in $100 \mu \mathrm{l}$ loading and washing buffer containing $80 \% \mathrm{ACN}$ in $1 \%$ aqueous (both $\mathrm{v} / \mathrm{v}$ ) TFA. Peptides were loaded onto a primed custom-made HILIC SPE micro-column according to Mysling et al. [30] packed with PolyHYDROXYETHYL A ${ }^{\text {TM }}$ resin (PolyLC Inc) onto a supporting $\mathrm{C} 8$ disk (Empore) in a p200 pipette tip. The flow-through fraction was collected. The HILIC SPE columns were then washed in $100 \mu$ l loading and washing buffer and the wash fraction was collected and combined with the first flow-through fraction for separate downstream analysis. The enriched glycopeptides were eluted with $50 \mu \mathrm{l} 0.1 \%(\mathrm{v} / \mathrm{v})$ TFA followed by $50 \mu \mathrm{l}$ $25 \mathrm{mM} \mathrm{NH}_{4} \mathrm{HCO}_{3}$ and finally $50 \mu 150 \%$ (v/v) ACN; these three elute fractions were combined. The flow through and the combined elute fraction were dried by vacuum centrifugation and purified on a primed Oligo R3 reversed phase SPE micro-column, aliquoted and dried again by vacuum centrifugation. This produced an enriched glycopeptide fraction.

\section{PNGase F and sialidase treatment}

An aliquot of the $\mathrm{TiO}_{2}$ or HILIC SPE enriched (sialo)glycopeptides was resuspended in $50 \mathrm{mM}$ TEAB, pH 8.0 and simultaneously de- $N$-glycosylated using $500 \mathrm{U}$ $N$-glycosidase F (PNGase F) (New England Biolabs, Ipswich, MA) and de- $O$-sialylated using $0.1 \mathrm{U}$ broadspecificity sialidase A (Prozyme Hayward, CA). The PNGase $\mathrm{F}$ and sialidase treatment were carried out concomitantly for $12 \mathrm{~h}$ at $37^{\circ} \mathrm{C}$ with the purpose of achieving efficient de- $N$-glycosylation while rendering the $O$-glycopeptide more amendable to LC-MS/MS 
characterization. After incubation, the de- $N$-glycosylated and de- $O$-sialylated peptides were purified on a primed Oligo R3 reversed phase SPE micro-column, dried by vacuum centrifugation and reconstituted in $50 \mu 10.1 \%$ formic acid prior to LC-MS/MS analysis.

\section{HILIC HPLC pre-fractionation}

The desialylated glycopeptides enriched by $\mathrm{TiO}_{2}$ as well as the flow through containing asialoglycopeptides were resuspended in $90 \% \mathrm{ACN}$ in $0.1 \%$ (both $\mathrm{v} / \mathrm{v}$ ) aqueous TFA and injected onto an HPLC column $(320 \mu \mathrm{m}$ ID $\times$ $170 \mathrm{~mm}$ length) packed in-house using TSKgel Amide- 80 HILIC $5 \mu \mathrm{m}$ resin (Tosoh Bioscience) connected to an Agilent 1200 micro-HPLC instrument. Briefly, samples were suspended in solvent B containing $90 \% \mathrm{ACN}$ in $0.1 \%$ (both $\mathrm{v} / \mathrm{v}$ ) aqueous TFA. Peptides were loaded onto a $320 \mu \mathrm{m}$ peak HILIC LC column and eluted at $6 \mu \mathrm{l} / \mathrm{min}$ by decreasing the solvent B from $100-60 \%$ over $42 \mathrm{~min}$ [82]. Fractions were automatically collected in a 96 well plate at 1 min intervals after UV detection at $210 \mathrm{~nm}$ and dried by vacuum centrifugation, combined in $8-16$ relevant fractions according to the corresponding UV profile and stored at $-20^{\circ} \mathrm{C}$ until LC-MS/MS analysis.

\section{Mass spectrometry analysis}

The pre-fractionated peptides were resuspended in $0.1 \% \mathrm{FA}$ and automatically loaded on a trap column $(2 \mathrm{~cm} \times 100 \mu \mathrm{m}$ inner diameter) custom packed with ReproSil-Pur C18 AQ $5 \mu \mathrm{m}$ resin (Dr. Maisch, Ammerbuch-Entringen, Germany). A total of $\sim 1 \mu \mathrm{g}$ of peptide was injected. The peptides were separated at 250 $\mathrm{nl} / \mathrm{min}$ on an analytical column $(17 \mathrm{~cm} \times 75 \mu \mathrm{m})$ packed with $3 \mu \mathrm{m}$ resin of the same kind operated in reversed phase chromatography mode using an EASY-nanoLC system (Thermo Fisher Scientific, Odense, Denmark). The mobile phases were $95 \% \mathrm{ACN}$ in $0.1 \%$ (both $\mathrm{v} / \mathrm{v}$ ) aqueous FA (solvent B) and aqueous $0.1 \%(\mathrm{v} / \mathrm{v}) \mathrm{FA}$ (solvent A). The linear gradient of solvent A increased from 3\% to $28 \%$ over $52 \mathrm{~min}, 28-47 \%$ over $5 \mathrm{~min}, 45-100 \%$ over 5 min and $8 \mathrm{~min}$ at $100 \% \mathrm{~B}$. The nanoLC was connected to a Q Exactive HF Hybrid Quadrupole-Orbitrap mass spectrometer (Thermo Fisher Scientific) operating in positive ion mode and using data dependent acquisition. The Orbitrap acquired the full MS scan with an automatic gain control (AGC) target value of $3 \times 10^{6}$ ions and a maximum fill time of $100 \mathrm{~ms}$. Each MS scan was acquired at high-resolution 120,000 full width half maximum (FWHM) at $\mathrm{m} / z 200$ in the Orbitrap with a $\mathrm{m} / \mathrm{z}$ range of 400-1600 Da. The 10 most abundant precursor ions were selected from each MS full scan for higher-energy collision-induced dissociation (HCD) fragmentation using normalized collision energy (NCE) of 29\% if they were at least doubly charged. Fragmentation was performed at high resolution $(60,000$ FWHM) for a target of
$1 \times 10^{5}$ product ions and a maximum injection time of $200 \mathrm{~ms}$ using a precursor isolation window of $\mathrm{m} / \mathrm{z} 1.2$ and a dynamic exclusion of $30 \mathrm{~s}$ after a single isolation and fragmentation of a given precursor.

For parallel reaction monitoring (PRM), full MS scans were acquired at 60,000 , AGC target was $1 \times 10^{6}$, maximum injection time was $100 \mathrm{~ms}$ and the $\mathrm{m} / \mathrm{z}$ range was 700-1800. HCD fragmentation was performed using an inclusion list with the following parameters: 60,000 resolution for an ion target of $1 \times 10^{5}$ and a maximum injection time of $150 \mathrm{~ms}$ using an isolation window of $\mathrm{m} / \mathrm{z}$ 1.6 and a fixed lower $m / z$ of 110 .

\section{Analysis of intact $N$-glycopeptides}

Intact glycopeptide HCD-MS/MS fragment spectra from each sample were searched against defined protein and glycan search spaces using the Byonic software v2.6.46 (Protein Metrics, https://www.proteinmetrics. $\mathrm{com} /$ ) [83]. Searches were performed with the following fixed modifications: precursor ion mass tolerance of $10 \mathrm{ppm}$, product ion mass tolerance of $0.02 \mathrm{Da}$, carbamidomethylation of Cys, and strict trypsin specific cleavage with a maximum of two missed cleavages per peptide. Searches were also conducted with the following variable modifications: oxidation of Met $(+15.994 \mathrm{Da})$, TMT (+229.163) at N-term and K, and $N$-glycosylation of sequon-localized Asn with the predefined $N$-glycan database of 309 mammalian $N$-glycans without sodium or $O$-glycosylation of Thr and Ser with the predefined $O$-glycan database containing 78 common mammalian $O$-glycans without sodium available within Byonic. To narrow the protein search space only the list of glycoproteins identified by the detection of sequoncontaining de- $\mathrm{N}$-glycosylated peptides generated by PNGase $F$ treatment were used in the protein database for the identification of intact $N$-glycopeptides. For intact $O$-glycopeptides, a protein database was composed by glycoproteins annotated in UniProtKB. All searches were filtered to $<1 \%$ false discovery rate (FDR) at the protein level and $0 \%$ at the peptide level by using a decoy database of the reversed sequences of the list of proteins used for the original (forward) protein search space [84]. We conducted strict filtering criteria, where only glycopeptides identified with high score ID was considered (PEP 2D scores $<0.001$ ). PEP 2D scores less than 0.001 means that there is less than $0.1 \%$ chance of having an incorrectly annotated peptide (but not necessarily correct annotation of the site and glycan composition) of the glycopeptides [27]. Further manual validation was performed for glycopeptides with "difficult-to-assign" glyco-features e.g. NeuGc-containing glycopeptides were validated by searching for the diagnostic ions pertaining to NeuGc $\mathrm{m} / \mathrm{z}$ 308.090/290.090 at a mass tolerance of $10 \mathrm{ppm}$ [85]. Using oxonium ions to validate glycopeptides should be performed carefully since co-isolation of different intact 
glycopeptides within the same $\mathrm{m} / \mathrm{z}$ isolation window occurs especially in complex peptide samples. This was observed for some intact $N$-glycopeptides, which were tentatively assigned as non-NeuAc containing glycopeptides, but with a clear presence of $m / z 274 / 292$ oxonium ions in the corresponding HCD-MS/MS spectra, useful diagnostic ions for NeuAc-containing glycopeptides (Supplementary Figure 7).

\section{Protein identification and glycosylation site analysis}

For protein identification and glycosylation site analysis, LC-MS/MS raw files were imported into MaxQuant version 1.5.2.8 [53]. The database search engine Andromeda [86] was used to search the HCD- and CID-MS/MS spectra against a database composed of the reviewed UniProtKB human protein database (release April 15, 2015; 45,185 entries) with a precursor ion tolerance level of $4.5 \mathrm{ppm}$ and product ion mass accuracy thresholds of $20 \mathrm{ppm}$ and $0.5 \mathrm{Da}$ for HCD-MS/MS and CID-MS/MS, respectively. For the reporter fragment ions, the 10-plex TMT was included in the search parameters and enzyme specificity was set to trypsin with a maximum of two missed cleavages. Carbamidomethylation of Cys $(+57.021 \mathrm{Da})$ was set as a fixed modification, and oxidation of Met $(+15.994 \mathrm{Da})$, deamidation of Asn and $\mathrm{Gln}(+0.984 \mathrm{Da})$ and protein $N$-terminal acetylation $(+42.010 \mathrm{Da})$ were selected as variable modifications. Five variable modifications per peptide were allowed. All identifications were filtered in order to achieve 1\% PSM and Protein FDR. The reporter ion intensities for each PSM with PIF (precursor ion fraction) $>0.75$ were calculated using MaxQuant. The quantitation of the identified proteins was determined by reporter ion intensities using at least 1 razor/unique peptide.

After excluding peptides identified as potential contaminants or appearing in the reverse database, we manually filtered the peptides containing the deamidation sites located within the conserved $\mathrm{N}$-glycosylation motif i.e. $\mathrm{NxS} / \mathrm{T} / \mathrm{C}$ where $\mathrm{x} \neq \mathrm{P}$.

\section{Bioinformatic analysis}

Bioinformatic analyses were performed using Perseus v.1.5.4.1 which is available within MaxQuant. The reporter ion intensities from redundant peptides were summed. The quantitation of the identified de- $N$ glycopeptides and non-modified peptides was performed by normalizing the reporter ion intensities by $\log 2$ conversion and subtracting them by the $\log 2$ mean of each sample. The first biological replicate of the BPH sample did not cluster together with the rest of the samples as assessed by principal component analysis (PCA) and was therefore removed. Statistical tests were carried out using the Limma R package [36], which have been shown to perform well for proteomics data in the case of low replicate numbers and missing values [87]. Resulting $p$-values were corrected for multiple statistical testing and converted into false discovery rates of $q<0.25$.

PCA was constructed in the web-based chemometrics platform MetaboAnalyst version 2.0 [88]. Protein-protein interaction networks and enrichment analyses were performed using the STRING software [89].

\section{Lectin blotting analysis}

An aliquot of $20 \mu \mathrm{g}$ urinary proteins were separated by discontinuous electrophoresis (stacking gel consisting of $4 \%$ polyacrylamide and resolving gel consisting of $12 \%$ polyacrylamide) for $1 \mathrm{~h}$. The separated proteins were then transferred to a polyvinylidene fluoride (PVDF) membrane by wet electroblotting using the Tris/glycine transfer buffer overnight at $4^{\circ} \mathrm{C}$. PVDF membranes were blocked in TBS-T and 5\% BSA at room temperature for $1 \mathrm{~h}$. The membranes were incubated with the following lectins (all from Vector Laboratories, Burlingame, CA, USA) in TBST for $16 \mathrm{~h}$ at a dilution of 1:2000 (v:v) concanavalin A (Con A), Maackia amurensis lectin (MAL), wheat germ agglutinin (WGA), Aleuria aurantia lectin (AAL) and Ricinus communis agglutinin (RCA).

Then membranes were washed three times for 5 min each with TBS-T and incubated with streptavidinHRP conjugate (Vector Laboratories, Burlingame, CA, USA, 1:5,000 for Con A and 1:2,000 for AAL, MAL, WGA and RCA) at room temperature for $1 \mathrm{~h}$ followed by three washes with TBS-T. The PVDF membranes were analyzed with Western Blotting Analysis System Bio-Rad Image Lab ${ }^{\mathrm{TM}}$ Software (BIO-RAD). The subsequent densitometry analysis of the resulting bands was performed with the Image J Software or Image Lab.

\section{Abbreviations}

PSA: Prostate specific antigen; PCa: prostate cancer; BPH: benign prostatic hyperplasia; HILIC: hydrophilic interaction liquid chromatography; LCMS/MS: liquid chromatography-mass spectrometry; GS: Gleason score; SPE: solid phase extraction; TiO2: titanium dioxide; PCA: principal component analysis; Con A: concanavalin A; MAL: Maackia amurensis lectin; AAL: Aleuria aurantia lectin; RCA: Ricinus communis agglutinin; PLS-DA: partial least squares discriminant analysis; PRM: Parallel PSM: reaction monitoring; peptide-spectrum matches.

\section{Author contributions}

R.K. and G.P. designed the study, performed the experiments, analyzed the data and wrote the manuscript. L.R.F. performed mass spectrometry analysis. M.R.L. and G.P. supervised experiments. M.T.A. wrote and revised the 
manuscript. F.O., V.G., K.R.M.L., W.N., M.S., conducted the clinical sample collection, anatomopathological classification and gathered clinical information. All authors have read and agreed with the final version of the manuscript.

\section{CONFLICTS OF INTEREST}

The authors declare no competing financial interests.

\section{FUNDING}

CNPq (GP 441878/2014-8) and FAPESP (GP: 2014/06863-3) and Ricerca Finalizzata Young Investigator Grant from the Italian Minister of Health (GR11.172.1), Rebeca Kawahara is supported by FAPESP (2015/02866$0)$. The VILLUM Center for Bioanalytical Sciences at the University of Southern Denmark is acknowledged for access to their mass spectrometers.

\section{REFERENCES}

1. Siegel RL, Miller KD, Jemal A. Cancer statistics, 2016. CA Cancer J Clin. 2016; 66:7-30. https://doi.org/10.3322/ caac. 21332 .

2. Prensner JR, Rubin MA, Wei JT, Chinnaiyan AM. Beyond PSA: the next generation of prostate cancer biomarkers. Sci Transl Med. 2012; 4:127rv3. https://doi.org/10.1126/ scitranslmed.3003180.

3. Adhyam M, Gupta AK. A Review on the Clinical Utility of PSA in Cancer Prostate. Indian J Surg Oncol. 2012; 3:120 29. https://doi.org/10.1007/s13193-012-0142-6.

4. Dijkstra S, Mulders PF, Schalken JA. Clinical use of novel urine and blood based prostate cancer biomarkers: a review. Clin Biochem. 2014; 47:889-96. https://doi.org/10.1016/j. clinbiochem.2013.10.023.

5. Jamaspishvili T, Kral M, Khomeriki I, Student V, Kolar Z, Bouchal J. Urine markers in monitoring for prostate cancer. Prostate Cancer Prostatic Dis. 2010; 13:12-19. https://doi. org/10.1038/pcan.2009.31.

6. Wood SL, Knowles MA, Thompson D, Selby PJ, Banks RE. Proteomic studies of urinary biomarkers for prostate, bladder and kidney cancers. Nat Rev Urol. 2013; 10:20618. https://doi.org/10.1038/nrurol.2013.24.

7. Haj-Ahmad TA, Abdalla MA, Haj-Ahmad Y. Potential Urinary Protein Biomarker Candidates for the Accurate Detection of Prostate Cancer among Benign Prostatic Hyperplasia Patients. J Cancer. 2014; 5:103-14. https://doi. org/10.7150/jca.6890.

8. Jedinak A, Curatolo A, Zurakowski D, Dillon S, Bhasin MK, Libermann TA, Roy R, Sachdev M, Loughlin KR, Moses MA. Novel non-invasive biomarkers that distinguish between benign prostate hyperplasia and prostate cancer.
BMC Cancer. 2015; 15:259. https://doi.org/10.1186/ s12885-015-1284-z.

9. Durand G, Seta N. Protein glycosylation and diseases: blood and urinary oligosaccharides as markers for diagnosis and therapeutic monitoring. Clin Chem. 2000; 46:795-805.

10. Drake PM, Cho W, Li B, Prakobphol A, Johansen E, Anderson NL, Regnier FE, Gibson BW, Fisher SJ. Sweetening the pot: adding glycosylation to the biomarker discovery equation. Clin Chem. 2010; 56:223-36. https:// doi.org/10.1373/clinchem.2009.136333.

11. Chen K, Gentry-Maharaj A, Burnell M, Steentoft C, Marcos-Silva L, Mandel U, Jacobs I, Dawnay A, Menon U, Blixt O. Microarray Glycoprofiling of CA125 improves differential diagnosis of ovarian cancer. J Proteome Res. 2013; 12:1408-18. https://doi.org/10.1021/pr3010474.

12. Zhang D, Chen B, Wang Y, Xia P, He C, Liu Y, Zhang R, Zhang M, Li Z. Disease-specific IgG Fc N-glycosylation as personalized biomarkers to differentiate gastric cancer from benign gastric diseases. Sci Rep. 2016; 6:25957. https://doi. org/10.1038/srep25957.

13. Kirwan A, Utratna M, O’Dwyer ME, Joshi L, Kilcoyne M. Glycosylation-Based Serum Biomarkers for Cancer Diagnostics and Prognostics. Biomed Res Int. 2015; 2015:490531. https://doi.org/10.1155/2015/490531.

14. Belický Š, Tkac J. Can glycoprofiling be helpful in detecting prostate cancer? Chem Zvesti. 2015; 69:90-111. https://doi.org/10.1515/chempap-2015-0052.

15. Vermassen $T$, Van Praet C, Poelaert F, Lumen N, Decaestecker K, Hoebeke P, Van Belle S, Rottey S, Delanghe J. Diagnostic accuracy of urinary prostate protein glycosylation profiling in prostatitis diagnosis. Biochem Med (Zagreb). 2015; 25:439-49. https://doi.org/10.11613/ BM.2015.045.

16. Pinho SS, Reis CA. Glycosylation in cancer: mechanisms and clinical implications. Nat Rev Cancer. 2015; 15:54055. https://doi.org/10.1038/nrc3982.

17. Munkley J, Elliott DJ. Hallmarks of glycosylation in cancer. Oncotarget. 2016; 7:35478-89. https://doi.org/10.18632/ oncotarget.8155.

18. Munkley J, Mills IG, Elliott DJ. The role of glycans in the development and progression of prostate cancer. Nat Rev Urol. 2016; 13:324-33. https://doi.org/10.1038/ nrurol.2016.65.

19. Vermassen T, Van Praet C, Lumen N, Decaestecker K, Vanderschaeghe D, Callewaert N, Villeirs G, Hoebeke P, Van Belle S, Rottey S, Delanghe J. Urinary prostate protein glycosylation profiling as a diagnostic biomarker for prostate cancer. Prostate. 2015; 75:314-22. https://doi. org/10.1002/pros.22918.

20. Shah P, Wang X, Yang W, Toghi Eshghi S, Sun S, Hoti N, Chen L, Yang S, Pasay J, Rubin A, Zhang H. Integrated Proteomic and Glycoproteomic Analyses of Prostate Cancer Cells Reveal Glycoprotein Alteration in Protein Abundance 
and Glycosylation. Mol Cell Proteomics. 2015; 14:275363. https://doi.org/10.1074/mcp.M115.047928.

21. Liu Y, Chen J, Sethi A, Li QK, Chen L, Collins B, Gillet LC, Wollscheid B, Zhang H, Aebersold R. Glycoproteomic analysis of prostate cancer tissues by SWATH mass spectrometry discovers $\mathrm{N}$-acylethanolamine acid amidase and protein tyrosine kinase 7 as signatures for tumor aggressiveness. Mol Cell Proteomics. 2014; 13:1753-68. https://doi.org/10.1074/mcp.M114.038273.

22. Cima I, Schiess R, Wild P, Kaelin M, Schüffler P, Lange V, Picotti P, Ossola R, Templeton A, Schubert O, Fuchs T, Leippold T, Wyler S, et al. Cancer genetics-guided discovery of serum biomarker signatures for diagnosis and prognosis of prostate cancer. Proc Natl Acad Sci U S A. 2011; 108:3342-47. https://doi.org/10.1073/pnas.1013699108.

23. Thaysen-Andersen M, Packer NH. Advances in LC-MS/ MS-based glycoproteomics: getting closer to system-wide site-specific mapping of the $\mathrm{N}$ - and O-glycoproteome. Biochim Biophys Acta. 2014; 1844:1437-52. https://doi. org/10.1016/j.bbapap.2014.05.002.

24. Thaysen-Andersen M, Packer NH, Schulz BL. Maturing Glycoproteomics Technologies Provide Unique Structural Insights into the N-glycoproteome and Its Regulation in Health and Disease. Mol Cell Proteomics. 2016; 15:177390. https://doi.org/10.1074/mcp.O115.057638.

25. Cao L, Qu Y, Zhang Z, Wang Z, Prytkova I, Wu S. Intact glycopeptide characterization using mass spectrometry. Expert Rev Proteomics. 2016; 13:513-22. https://doi.org/ 10.1586/14789450.2016.1172965.

26. Tsai PL, Chen SF. A Brief Review of Bioinformatics Tools for Glycosylation Analysis by Mass Spectrometry. Mass Spectrom (Tokyo). 2017; 6:S0064. https://doi.org/10.5702/ massspectrometry.S0064.

27. Kawahara R, Saad J, Angeli CB, Palmisano G. Site-specific characterization of $\mathrm{N}$-linked glycosylation in human urinary glycoproteins and endogenous glycopeptides. Glycoconj J. 2016; 33:937-51. https://doi.org/10.1007/ s10719-016-9677-z.

28. Larsen MR, Jensen SS, Jakobsen LA, Heegaard NH. Exploring the sialiome using titanium dioxide chromatography and mass spectrometry. Mol Cell Proteomics. 2007; 6:1778-87. https://doi.org/10.1074/mcp. M700086-MCP200.

29. Palmisano G, Lendal SE, Engholm-Keller K, LethLarsen R, Parker BL, Larsen MR. Selective enrichment of sialic acid-containing glycopeptides using titanium dioxide chromatography with analysis by HILIC and mass spectrometry. Nat Protoc. 2010; 5:1974-82. https://doi. org/10.1038/nprot.2010.167.

30. Mysling S, Palmisano G, Højrup P, Thaysen-Andersen M. Utilizing ion-pairing hydrophilic interaction chromatography solid phase extraction for efficient glycopeptide enrichment in glycoproteomics. Anal Chem. 2010; 82:5598-609. https://doi.org/10.1021/ac100530w.
31. Thaysen-Andersen M, Mysling S, Højrup P. Site-specific glycoprofiling of N-linked glycopeptides using MALDITOF MS: strong correlation between signal strength and glycoform quantities. Anal Chem. 2009; 81:3933-43. https://doi.org/10.1021/ac900231w.

32. Bern MW, Kil YJ. Two-dimensional target decoy strategy for shotgun proteomics. J Proteome Res. 2011; 10:5296301. https://doi.org/10.1021/pr200780j.

33. Palmisano G, Parker BL, Engholm-Keller K, Lendal SE, Kulej K, Schulz M, Schwämmle V, Graham ME, Saxtorph H, Cordwell SJ, Larsen MR. A novel method for the simultaneous enrichment, identification, and quantification of phosphopeptides and sialylated glycopeptides applied to a temporal profile of mouse brain development. Mol Cell Proteomics. 2012; 11:1191-202. https://doi.org/10.1074/ mcp.M112.017509.

34. Houel S, Hilliard M, Yu YQ, McLoughlin N, Martin SM, Rudd PM, Williams JP, Chen W. N- and O-glycosylation analysis of etanercept using liquid chromatography and quadrupole time-of-flight mass spectrometry equipped with electron-transfer dissociation functionality. Anal Chem. 2014; 86:576-84. https://doi.org/10.1021/ac402726h.

35. Maupin KA, Liden D, Haab BB. The fine specificity of mannose-binding and galactose-binding lectins revealed using outlier motif analysis of glycan array data. Glycobiology. 2012; 22:160-69. https://doi.org/10.1093/ glycob/cwr128.

36. Ritchie ME, Phipson B, Wu D, Hu Y, Law CW, Shi W, Smyth GK. limma powers differential expression analyses for RNA-sequencing and microarray studies. Nucleic Acids Res. 2015; 43:e47. https://doi.org/10.1093/nar/gkv007.

37. Peterson AC, Russell JD, Bailey DJ, Westphall MS, Coon JJ. Parallel reaction monitoring for high resolution and high mass accuracy quantitative, targeted proteomics. Mol Cell Proteomics. 2012; 11:1475-88. https://doi.org/10.1074/ mcp.O112.020131.

38. Campbell MP, Peterson R, Mariethoz J, Gasteiger E, Akune Y, Aoki-Kinoshita KF, Lisacek F, Packer NH. UniCarbKB: building a knowledge platform for glycoproteomics. Nucleic Acids Res. 2014; 42:D215-21. https://doi. org/10.1093/nar/gkt1128.

39. Samraj AN, Läubli H, Varki N, Varki A. Involvement of a non-human sialic Acid in human cancer. Front Oncol. 2014; 4:33.

40. Davalieva K, Kiprijanovska S, Komina S, Petrusevska G, Zografska NC, Polenakovic M. Proteomics analysis of urine reveals acute phase response proteins as candidate diagnostic biomarkers for prostate cancer. Proteome Sci. 2015; 13:2. https://doi.org/10.1186/s12953-014-0059-9.

41. Xu C, Jung M, Burkhardt M, Stephan C, Schnorr D, Loening S, Jung K, Dietel M, Kristiansen G. Increased CD59 protein expression predicts a PSA relapse in patients after radical prostatectomy. Prostate. 2005; 62:224-32. https://doi.org/10.1002/pros.20134. 
42. Jarvis GA, Li J, Hakulinen J, Brady KA, Nordling $\mathrm{S}$, Dahiya R, Meri S. Expression and function of the complement membrane attack complex inhibitor protectin (CD59) in human prostate cancer. Int J Cancer. 1997; 71:1049-55. https://doi.org/10.1002/(SICI)10970215(19970611)71:6<1049::AID-IJC22>3.0.CO;2-7.

43. Saraon P, Musrap N, Cretu D, Karagiannis GS, Batruch I, Smith C, Drabovich AP, Trudel D, van der Kwast T, Morrissey C, Jarvi KA, Diamandis EP. Proteomic profiling of androgen-independent prostate cancer cell lines reveals a role for protein $\mathrm{S}$ during the development of high grade and castration-resistant prostate cancer. J Biol Chem. 2012; 287:34019-31. https://doi.org/10.1074/jbc.M112.384438.

44. Rizzi F, Bettuzzi S. Targeting Clusterin in prostate cancer. J Physiol Pharmacol. 2008 (Suppl 9); 59:265-74.

45. Pins MR, Fiadjoe JE, Korley F, Wong M, Rademaker AW, Jovanovic B, Yoo TK, Kozlowski JM, Raji A, Yang XJ, Lee C. Clusterin as a possible predictor for biochemical recurrence of prostate cancer following radical prostatectomy with intermediate Gleason scores: a preliminary report. Prostate Cancer Prostatic Dis. 2004; 7:243-48. https://doi.org/10.1038/sj.pcan.4500722.

46. Halim A, Nilsson J, Rüetschi U, Hesse C, Larson G. Human urinary glycoproteomics; attachment site specific analysis of $\mathrm{N}$ - and O-linked glycosylations by CID and ECD. Mol Cell Proteomics. 2012; 11:M111.013649. https://doi. org/10.1074/mcp.M111.013649.

47. Saraswat M, Joenväära S, Musante L, Peltoniemi H, Holthofer H, Renkonen R. N-linked (N-) glycoproteomics of urinary exosomes. [Corrected]. Mol Cell Proteomics. 2015; $\quad$ 14:263-76. $\quad$ https://doi.org/10.1074/mcp. M114.040345. Erratum in: N-linked (N-) Glycoproteomics of Urinary Exosomes. [Mol Cell Proteomics. 2015].

48. Nagaraj N, Mann M. Quantitative analysis of the intra- and inter-individual variability of the normal urinary proteome. J Proteome Res. 2011; 10:637-45. https://doi.org/10.1021/ pr100835s.

49. Maes E, Valkenborg D, Baggerman G, Willems H, Landuyt B, Schoofs L, Mertens I. Determination of variation parameters as a crucial step in designing TMT-based clinical proteomics experiments. PLoS One. 2015; 10:e0120115. https://doi.org/10.1371/journal.pone.0120115.

50. Ahrné E, Glatter T, Viganò C, Schubert C, Nigg EA, Schmidt A. Evaluation and Improvement of Quantification Accuracy in Isobaric Mass Tag-Based Protein Quantification Experiments. J Proteome Res. 2016; 15:2537-47. https:// doi.org/10.1021/acs.jproteome.6b00066.

51. Karp NA, Huber W, Sadowski PG, Charles PD, Hester SV, Lilley KS. Addressing accuracy and precision issues in iTRAQ quantitation. Mol Cell Proteomics. 2010; 9:188597. https://doi.org/10.1074/mcp.M900628-MCP200.

52. Christoforou AL, Lilley KS. Isobaric tagging approaches in quantitative proteomics: the ups and downs. Anal Bioanal
Chem. 2012; 404:1029-37. https://doi.org/10.1007/ s00216-012-6012-9.

53. Cox J, Mann M. MaxQuant enables high peptide identification rates, individualized p.p.b.-range mass accuracies and proteome-wide protein quantification. Nat Biotechnol. 2008; 26:1367-72. https://doi.org/10.1038/ nbt.1511.

54. Fuster MM, Esko JD. The sweet and sour of cancer: glycans as novel therapeutic targets. Nat Rev Cancer. 2005; 5:52642. https://doi.org/10.1038/nrc1649.

55. Padler-Karavani V. Aiming at the sweet side of cancer: aberrant glycosylation as possible target for personalizedmedicine. Cancer Lett. 2014; 352:102-12. https://doi. org/10.1016/j.canlet.2013.10.005.

56. Meany DL, Chan DW. Aberrant glycosylation associated with enzymes as cancer biomarkers. Clin Proteomics. 2011; 8:7. https://doi.org/10.1186/1559-0275-8-7.

57. Wang X, Chen J, Li QK, Peskoe SB, Zhang B, Choi C, Platz EA, Zhang H. Overexpression of $\alpha(1,6)$ fucosyltransferase associated with aggressive prostate cancer. Glycobiology. 2014; 24:935-44. https://doi.org/10.1093/glycob/cwu051.

58. Vermassen T, Van Praet C, Vanderschaeghe D, Maenhout T, Lumen N, Callewaert N, Hoebeke P, Van Belle S, Rottey $\mathrm{S}$, Delanghe J. Capillary electrophoresis of urinary prostate glycoproteins assists in the diagnosis of prostate cancer. Electrophoresis. 2014; 35:1017-24. https://doi.org/10.1002/ elps.201300332.

59. Meany DL, Zhang Z, Sokoll LJ, Zhang H, Chan DW. Glycoproteomics for prostate cancer detection: changes in serum PSA glycosylation patterns. J Proteome Res. 2009; 8:613-19. https://doi.org/10.1021/pr8007539.

60. Barfeld SJ, East P, Zuber V, Mills IG. Meta-analysis of prostate cancer gene expression data identifies a novel discriminatory signature enriched for glycosylating enzymes. BMC Med Genomics. 2014; 7:513. https://doi. org/10.1186/s12920-014-0074-9.

61. Tabarés G, Radcliffe CM, Barrabés S, Ramírez M, Aleixandre RN, Hoesel W, Dwek RA, Rudd PM, Peracaula $\mathrm{R}$, de Llorens R. Different glycan structures in prostatespecific antigen from prostate cancer sera in relation to seminal plasma PSA. Glycobiology. 2006; 16:132-45. https://doi.org/10.1093/glycob/cwj042.

62. Llop E, Ferrer-Batallé M, Barrabés S, Guerrero PE, Ramírez M, Saldova R, Rudd PM, Aleixandre RN, Comet J, de Llorens R, Peracaula R. Improvement of Prostate Cancer Diagnosis by Detecting PSA Glycosylation-Specific Changes. Theranostics. 2016; 6:1190-204. https://doi. org/10.7150/thno. 15226 .

63. Ohyama C, Hosono M, Nitta K, Oh-eda M, Yoshikawa K, Habuchi T, Arai Y, Fukuda M. Carbohydrate structure and differential binding of prostate specific antigen to Maackia amurensis lectin between prostate cancer and benign 
prostate hypertrophy. Glycobiology. 2004; 14:671-79. https://doi.org/10.1093/glycob/cwh071.

64. Babiker AA, Nilsson B, Ronquist G, Carlsson L, Ekdahl KN. Transfer of functional prostasomal CD59 of metastatic prostatic cancer cell origin protects cells against complement attack. Prostate. 2005; 62:105-14. https://doi. org/10.1002/pros.20102.

65. Rudd PM, Morgan BP, Wormald MR, Harvey DJ, van den Berg CW, Davis SJ, Ferguson MA, Dwek RA. The glycosylation of the complement regulatory protein, human erythrocyte CD59. J Biol Chem. 1997; 272:7229-44. https://doi.org/10.1074/jbc.272.11.7229.

66. Tokugawa Y, Kunishige I, Kubota Y, Shimoya K, Nobunaga T, Kimura T, Saji F, Murata Y, Eguchi N, Oda H, Urade Y, Hayaishi O. Lipocalin-type prostaglandin D synthase in human male reproductive organs and seminal plasma. Biol Reprod. 1998; 58:600-07. https://doi.org/10.1095/ biolreprod58.2.600.

67. Jørgensen A, Nielsen JE, Nielsen BF, Morthorst JE, Bjerregaard P, Leffers H. Expression of prostaglandin synthases (pgds and pges) during zebrafish gonadal differentiation. Comp Biochem Physiol A Mol Integr Physiol. 2010; 157:102-08. https://doi.org/10.1016/j. cbpa.2010.03.014.

68. Moniot B, Farhat A, Aritake K, Declosmenil F, Nef S, Eguchi N, Urade Y, Poulat F, Boizet-Bonhoure B. Hematopoietic prostaglandin D synthase (H-Pgds) is expressed in the early embryonic gonad and participates to the initial nuclear translocation of the SOX9 protein. Dev Dyn. 2011; 240:2335-43. https://doi.org/10.1002/ dvdy.22726.

69. Badawi AF. The role of prostaglandin synthesis in prostate cancer. BJU Int. 2000; 85:451-62. https://doi. org/10.1046/j.1464-410x.2000.00507.x.

70. Ragolia L, Hall CE, Palaia T. Post-translational modification regulates prostaglandin D2 synthase apoptotic activity: characterization by site-directed mutagenesis. Prostaglandins Other Lipid Mediat. 2007; 83:25-32. https:// doi.org/10.1016/j.prostaglandins.2006.09.006.

71. Kim Y, Jeon J, Mejia S, Yao CQ, Ignatchenko V, Nyalwidhe JO, Gramolini AO, Lance RS, Troyer DA, Drake RR, Boutros PC, Semmes OJ, Kislinger T. Targeted proteomics identifies liquid-biopsy signatures for extracapsular prostate cancer. Nat Commun. 2016; 7:11906. https://doi. org/10.1038/ncomms11906.

72. Song E, Pyreddy S, Mechref Y. Quantification of glycopeptides by multiple reaction monitoring liquid chromatography/tandem mass spectrometry. Rapid Commun Mass Spectrom. 2012; 26:1941-54. https://doi. org/10.1002/rcm.6290.

73. de la Fouchardière C, Flechon A, Droz JP. Coagulopathy in prostate cancer. Neth J Med. 2003; 61:347-54.

74. Navarro M, Ruiz I, Martín G, Cruz JJ. Patient with disseminated intravascular coagulation as the first manifestation of adenocarcinoma of the prostate. Risks of prostatic biopsy. Prostate Cancer Prostatic Dis. 2006; 9:190-91. https://doi.org/10.1038/sj.pcan.4500854.

75. Adamson AS, Francis JL, Witherow RO, Snell ME. Coagulopathy in the prostate cancer patient: prevalence and clinical relevance. Ann R Coll Surg Engl. 1993; 75:100-04.

76. Duran I, Tannock IF. Disseminated intravascular coagulation as the presenting sign of metastatic prostate cancer. J Gen Intern Med. 2006; 21:C6-8. https://doi. org/10.1111/j.1525-1497.2006.00506.x.

77. Ong SY, Taverna J, Jokerst C, Enzler T, Hammode E, Rogowitz E, Green MR, Babiker HM. Prostate CancerAssociated Disseminated Intravascular Coagulation with Excessive Fibrinolysis Treated with Degarelix. Case Rep Oncol Med. 2015; 2015:212543. https://doi. org/10.1155/2015/212543.

78. Pio R, Corrales L, Lambris JD. The role of complement in tumor growth. Adv Exp Med Biol. 2014; 772:229-62. https://doi.org/10.1007/978-1-4614-5915-6_11.

79. Pio R, Ajona D, Lambris JD. Complement inhibition in cancer therapy. Semin Immunol. 2013; 25:54-64. https:// doi.org/10.1016/j.smim.2013.04.001.

80. Kawahara R, Meirelles GV, Heberle H, Domingues RR, Granato DC, Yokoo S, Canevarolo RR, Winck FV, Ribeiro AC, Brandão TB, Filgueiras PR, Cruz KS, Barbuto JA, et al. Integrative analysis to select cancer candidate biomarkers to targeted validation. Oncotarget. 2015; 6:43635-52. https:// doi.org/10.18632/oncotarget.6018.

81. Manning ML, Williams SA, Jelinek CA, Kostova MB, Denmeade SR. Proteolysis of complement factors iC3b and $\mathrm{C} 5$ by the serine protease prostate-specific antigen in prostatic fluid and seminal plasma. J Immunol. 2013; 190:2567-74. https://doi.org/10.4049/jimmunol.1200856.

82. Huang H, Haar Petersen M, Ibañez-Vea M, Lassen PS, Larsen MR, Palmisano G. Simultaneous Enrichment of Cysteine-containing Peptides and Phosphopeptides Using a Cysteine-specific Phosphonate Adaptable Tag (CysPAT) in Combination with titanium dioxide (TiO2) Chromatography. Mol Cell Proteomics. 2016; 15:32823296. https://doi.org/10.1074/mcp.M115.054551.

83. Bern M, Kil YJ, Becker C. Byonic: advanced peptide and protein identification software. Curr Protoc Bioinformatics. 2012; Chapter 13:Unit13.20. https://doi. org/10.1002/0471250953.bi1320s40.

84. Bern M, Cai Y, Goldberg D. Lookup peaks: a hybrid of de novo sequencing and database search for protein identification by tandem mass spectrometry. Anal Chem. 2007; 79:1393-400. https://doi.org/10.1021/ac0617013.

85. Lee LY, Moh ES, Parker BL, Bern M, Packer NH, Thaysen-Andersen M. Toward Automated N-Glycopeptide Identification in Glycoproteomics. J Proteome Res. 2016; 15:3904-15. https://doi.org/10.1021/acs.jproteome.6b00438.

86. Cox J, Neuhauser N, Michalski A, Scheltema RA, Olsen JV, Mann M. Andromeda: a peptide search engine integrated 
into the MaxQuant environment. J Proteome Res. 2011; 10:1794-805. https://doi.org/10.1021/pr101065j.

87. Schwämmle V, León IR, Jensen ON. Assessment and improvement of statistical tools for comparative proteomics analysis of sparse data sets with few experimental replicates. J Proteome Res. 2013; 12:3874-83. https://doi. org/10.1021/pr400045u.

88. Xia J, Sinelnikov IV, Han B, Wishart DS. MetaboAnalyst 3.0 - making metabolomics more meaningful. Nucleic
Acids Res. 2015; 43:W251-7. https://doi.org/10.1093/nar/ gkv380.

89. Shannon P, Markiel A, Ozier O, Baliga NS, Wang JT, Ramage D, Amin N, Schwikowski B, Ideker T. Cytoscape: a software environment for integrated models of biomolecular interaction networks. Genome Res. 2003; 13:2498-504. https://doi.org/10.1101/gr.1239303. 